\title{
A Promising Nano-Insulating-Oil for Industrial Application: Electrical Properties and Modification Mechanism
}

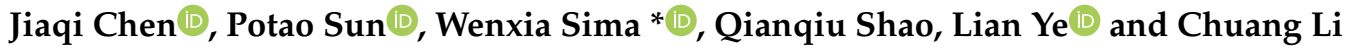 \\ State Key Laboratory of Power Transmission Equipment \& System Security and New Technology, \\ Chongqing University, Chongqing 400030, China; jqch@cqu.edu.cn (J.C.); sunpotao@cqu.edu.cn (P.S.); \\ shaoqianqiu@cqu.edu.cn (Q.S.); yelian@cqu.edu.cn (L.Y.); lichuang123cqu@163.com (C.L.) \\ * Correspondence: cqsmwx@cqu.edu.cn; Tel.: +86-139-9686-7420
}

Received: 28 April 2019; Accepted: 21 May 2019; Published: 23 May 2019

\begin{abstract}
Despite being discovered more than 20 years ago, nanofluids still cannot be used in the power industry. The fundamental reason is that nano-insulating oil has poor stability, and its electrical performance decreases under negative impulse voltage. We found that $C_{60}$ nanoparticles can maintain long-term stability in insulating oil without surface modification. $\mathrm{C}_{60}$ has strong electronegativity and photon absorption ability, which can comprehensively improve the electrical performance of insulating oil. This finding has great significance for the industrial application of nano-insulating oil. In this study, six concentrations of nano- $\mathrm{C}_{60}$ modified insulating oil (CMIO) were prepared, and their breakdown strength and dielectric properties were tested. The thermally stimulated current (TSC) curves of fresh oil (FO) and CMIO were experimentally determined. The test results indicate that $\mathrm{C}_{60}$ nanoparticles can simultaneously improve the positive and negative lightning impulse and power frequency breakdown voltage of insulating oil, while hardly increasing dielectric loss. At $150 \mathrm{mg} / \mathrm{L}$, the positive and negative lightning impulse breakdown voltages of CMIO increased by $7.51 \%$ and $8.33 \%$, respectively, compared with those of FO. The AC average breakdown voltage reached its peak (18.0\% higher compared with FO) at a CMIO concentration of $200 \mathrm{mg} / \mathrm{L}$. Based on the test results and the special properties of $\mathrm{C}_{60}$, we believe that changes in the trap parameters, the strong electron capture ability of $\mathrm{C}_{60}$, and the absorption capacity of $\mathrm{C}_{60}$ for photons enhanced the breakdown performance of insulating oil by $\mathrm{C}_{60}$ nanoparticles.
\end{abstract}

Keywords: $\mathrm{C}_{60}$ nanoparticles; electrical properties; insulating oil; modification mechanism; thermally stimulated current (TSC)

\section{Introduction}

Numerous studies on nano-insulating oil have been conducted since Argonne Laboratory proposed the concept of nanofluids in 1995 [1]. Thus far, no nano-insulating oil that can be used in the power industry has been discovered owing to the constraints caused by the following factors.

\subsection{Long-Term Stability}

Conventional nanoparticles (such as $\mathrm{Fe}_{3} \mathrm{O}_{4}, \mathrm{TiO}_{2}$, and $\mathrm{Al}_{2} \mathrm{O}_{3}$ ) are insoluble in oil. Matching surface modifiers must be used to ensure the long-term stability of these nanoparticles [2-4]. However, surface modifiers may deteriorate and fall off in long-term complex environments (such as heat, electricity, and magnetism), which weaken the dispersion of nanoparticles. Moreover, an improper amount of surface modifier may adversely affect the viscosity, as well as the physical and chemical stability, of the modified oil and even the heat transfer performance of nanoparticles [4]. 


\subsection{Decrease in Negative Impulse Breakdown Performance}

The positive impulse breakdown performance of most nano-insulating oils obviously improves. However, their negative impulse breakdown performance decreases to varying degrees, as shown in Table 1.

Table 1. Reduction of negative lightning impulse breakdown voltage of nano-insulating oil relative to host oil reported in the literature.

\begin{tabular}{cccccc}
\hline $\mathbf{N P}^{1} / \mathrm{Oil} \mathrm{System}$ & $\begin{array}{c}\text { Nanoparticle } \\
\text { Type }\end{array}$ & Concentration & Size of NP & $\begin{array}{c}\text { Percentage } \\
\text { Increase }\end{array}$ & Ref \\
\hline $\mathrm{Fe}_{3} \mathrm{O}_{4} / \mathrm{U}-60^{2}$ & Conductor & $\mathrm{NM}^{6}$ & $<10 \mathrm{~nm}$ & $-9.41 \%$ & {$[5]$} \\
$\mathrm{Fe}_{3} \mathrm{O}_{4} / \mathrm{Nytro}^{3}$ & Conductor & $\mathrm{NM}$ & $<10 \mathrm{~nm}$ & $-2.26 \%$ & {$[5]$} \\
$\mathrm{Fe}_{3} \mathrm{O}_{4} / \# 25 \mathrm{MO}{ }^{4}$ & Conductor & $0.03 \mathrm{~g} / \mathrm{L}$ & $20 \mathrm{~nm}$ & $-15.82 \%$ & {$[6]$} \\
$\mathrm{TiO}_{2} / \# 25 \mathrm{MO}$ & Semiconductor & $0.01 \mathrm{~g} / \mathrm{L}$ & $20 \mathrm{~nm}$ & $-3.39 \%$ & {$[6]$} \\
$\mathrm{Al}_{2} \mathrm{O}_{3} / \# 25 \mathrm{MO}$ & Insulator & $0.02 \mathrm{~g} / \mathrm{L}$ & $20 \mathrm{~nm}$ & $-2.53 \%$ & {$[6]$} \\
$\left(\mathrm{Fe}_{3} \mathrm{O}_{4} / \mathrm{MO}\right) \mathrm{Aged}$ & Conductor & $\mathrm{NM}$ & $<10 \mathrm{~nm}$ & $-7.75 \%$ & {$[7]$} \\
$\mathrm{TiO}_{2} / \# 25 \mathrm{MO}$ & Semiconductor & $5 \% w / v$ & $<50 \mathrm{~nm}$ & $-4.49 \%$ & {$[8]$} \\
$\mathrm{Al}_{2} \mathrm{O}_{3} / \# 25 \mathrm{MO}$ & Insulator & $5 \% w / v$ & $<50 \mathrm{~nm}$ & $-7.34 \%$ & {$[8]$} \\
$\mathrm{Fe}_{3} \mathrm{O}_{4} / \# 25 \mathrm{MO}$ & Conductor & $5 \% w / v$ & $<50 \mathrm{~nm}$ & $-6.12 \%$ & {$[8]$} \\
$\mathrm{Al}_{2} \mathrm{O}_{3} / \# 25 \mathrm{MO}$ & Insulator & $20 \% w / v$ & $\mathrm{NM}$ & $-9.98 \%$ & {$[9]$} \\
$\mathrm{TiO}_{2} / \# 25 \mathrm{MO}$ & Semiconductor & $0.075 \% v / v$ & $<10 \mathrm{~nm}$ & $-6.84 \%$ & {$[10]$} \\
$\mathrm{SiO}_{2} / \# 25 \mathrm{MO}$ & Insulator & $20 \% w / v$ & $\mathrm{NM}$ & $-5.93 \%$ & {$[11]$} \\
$\mathrm{ZnO}_{2} / \# 25 \mathrm{MO}$ & Semiconductor & $0.0475 \% v / v$ & $5 \sim 20 \mathrm{~nm}$ & $-34.4 \%$ & {$[12]$} \\
$\mathrm{Al}_{2} \mathrm{O}_{3} / \# 25 \mathrm{MO}$ & Insulator & $0.1425 \% v / v$ & $5 \sim 20 \mathrm{~nm}$ & $-13.0 \%$ & {$[12]$} \\
\hline
\end{tabular}

\footnotetext{
${ }^{1}$ Nanoparticle; ${ }^{2}$ Univolt 60 Exxon mineral oil; ${ }^{3}$ Nytro $10 X$ mineral oil; ${ }^{4}$ \#25 mineral oil $;{ }^{5}$ Compared with aged $\mathrm{MO} ;{ }^{6}$ Not mentioned.
}

More than $90 \%$ of the lightning that occurs in nature is of negative polarity [13], therefore the decline in the negative impulse breakdown performance of nano-insulating oil restricts its application in power transformers [14].

\subsection{Significant Increase in Dielectric Loss}

The improvement of electrical properties of nano-insulating oil may be accompanied by a substantial increase in dielectric loss. This increase affects the heat dissipation of the transformer and accelerates the thermal aging of the dielectric.

Table 2 shows the results of the electrical performance test performed by Sartoratto [15] on $\mathrm{Fe}_{3} \mathrm{O}_{4}$ nanoparticle-modified insulating oil. The table shows that $\mathrm{Fe}_{3} \mathrm{O}_{4}$ nanoparticles (average nanoparticle size is $7.4 \mathrm{~nm}$ ) increase the breakdown voltage of insulating oil and induce a significant increase in dielectric loss. Liu [12] and Mergos [16] have also observed this phenomenon in insulating oils modified by other nanoparticles such as $\mathrm{ZnO}, \mathrm{TiO}_{2}$, and $\mathrm{CuO}$.

Table 2. Electrical properties of magnetic fluids compared with those of pure insulating oil.

\begin{tabular}{cccc}
\hline Volume Fraction (\%) & Loss Factor & Growth Multiple of Loss Factor & Dielectric Strength (kV) \\
\hline 0.0 & 0.00366 & 1 & 70 \\
0.800 & 2.389 & 653 & - \\
0.016 & 0.399 & 109 & 79 \\
0.0080 & 0.1868 & 51 & 72 \\
0.0040 & 0.1274 & 35 & 70 \\
\hline
\end{tabular}

Recently, we have found that nano-insulating oil made of $\mathrm{C}_{60}$ nanoparticles can greatly overcome these three problems due to its excellent properties. Theoretical calculations show that the electron affinity potential of $\mathrm{C}_{60}$ is approximately $2.683 \mathrm{eV}$ [17], which is higher than that of the excellent gas-insulating medium $\mathrm{SF}_{6}$ (electron affinity is approximately $1.06 \mathrm{eV}$ [18]). Therefore, $\mathrm{C}_{60}$ has a strong 
adsorption capacity for electrons. A single molecule can accept at least six electrons [19]. Moreover, $\mathrm{C}_{60}$ can absorb a large number of photons through photopolymerization [20]. The $\mathrm{C}_{60}$ molecule is soluble in organic solvents, especially aromatic solvents with large $\pi$ bonds [21,22]. Therefore, $\mathrm{C}_{60}$ nanoparticles have a certain natural solubility in transformer insulating oils (the main component contains aromatic hydrocarbons) that are nonpolar solvents.

In this study, a new type of nanofluid was prepared by dispersing $C_{60}$ nanoparticles into insulating oil without the use of a surface modifier. The breakdown strength and dielectric properties of the prepared samples were tested, and the thermally stimulated current (TSC) curves of fresh oil (FO) and nano- $\mathrm{C}_{60}$ modified insulating oil (CMIO) were experimentally determined. We discuss the mechanism involved in the enhancement of the breakdown performance of insulating oil on this basis.

\section{Experimental Setup}

\subsection{Preparation of Nanofluids}

Transformer mineral oil (\#25) and 99.9\% pure $\mathrm{C}_{60}$ powder (Tanfeng Tech, Suzhou, China) were used in the tests. The technical specifications of the mineral oil satisfied the international standard ASTM D3487-2000(II) [23].

The surface modifier may adversely affect oil material stability and heat transfer performance. Given that $\mathrm{C}_{60}$ particles have a certain solubility in insulating oil, surface modifiers were not used in the experiments. The photopolymerization of $\mathrm{C}_{60}$ can be prevented by protecting $\mathrm{CMIO}$ from light during preparation [24].

Pretreatments were carried out on all experimental samples as follows: First, mineral oil (\#25) was filtered through a membrane filter for the removal of contaminants (the quality of the oil meets the requirement of CIGRE working group 12.17: particle content with a diameter larger than $5 \mu \mathrm{m}$ is lower than 300 per $100 \mathrm{~mL}$ ). Then, $\mathrm{C}_{60}$ particles and insulating oil were separately dried at $90{ }^{\circ} \mathrm{C}$ for $48 \mathrm{~h}$ in a vacuum drying oven. Finally, the mechanical grinding of the $\mathrm{C}_{60}$ nanoparticles and vacuum degassing of the insulating oil were performed.

Ultrasonication can effectively break the agglomeration and reduce particle size in fluid [25]. After the pretreatments, the $\mathrm{C}_{60}$ nanoparticles were placed in the insulating oil and ultrasonically dispersed at $60{ }^{\circ} \mathrm{C}$ for at least $60 \mathrm{~min}$ (sx-sonic FS-1800N, maximum volume $=3 \mathrm{~L}$, ultrasonic peak output $=1800 \mathrm{~W}$, frequency $=20 \mathrm{kHz}$, ultrasonic horn diameter $=20 \mathrm{~mm}$ ). The ultrasonic power used in the test was $70 \%$ of the maximum output power. After 6 seconds of continuous ultrasonic operation, it stopped for 6 seconds and then started the next operation (instrument setting) to prevent the ultrasonic horn and sample temperature from being too high. The applied energy per volume (weight) of nanoparticle material in suspension was estimated to be ca. $37.8 \mathrm{~kJ}$ per $50 \mathrm{~mL}$ of particles $(0.015 \mathrm{~g})$. The kinematic viscosity of the oil sample was approximately $10.8 \mathrm{~mm}^{2} / \mathrm{s}\left(40^{\circ} \mathrm{C}\right)$. Mechanical agitation was required for $5 \mathrm{~min}$ after each $15 \mathrm{~min}$ of ultrasonication. CMIO samples with concentrations of 50, 100, 150, 200, 250 , and $300 \mathrm{mg} / \mathrm{L}$ were prepared and dried in a vacuum oven for $48 \mathrm{~h}$ at $60^{\circ} \mathrm{C}$.

\subsection{AC Breakdown Tests}

A Portable Oil Tester IJJD-80 (Ruixin Electric, Wuhan, China) (Figure 1) was used to measure AC breakdown voltage according to IEC-60156 [26]. The gap between the brass electrodes was set at $2.5 \mathrm{~mm}$. A $50 \mathrm{~Hz}$ AC voltage with a rising rate of $2 \mathrm{kV} / \mathrm{s}$ was applied to the oil cup. The initial standing time was set at $5 \mathrm{~min}$ before the application of voltage. The time interval with stirring action and standing time after each breakdown were set at $2 \mathrm{~min}$. Each sample was tested six times, and the average value was taken as the power-frequency breakdown voltage value. All the experiments were performed at room temperature. 


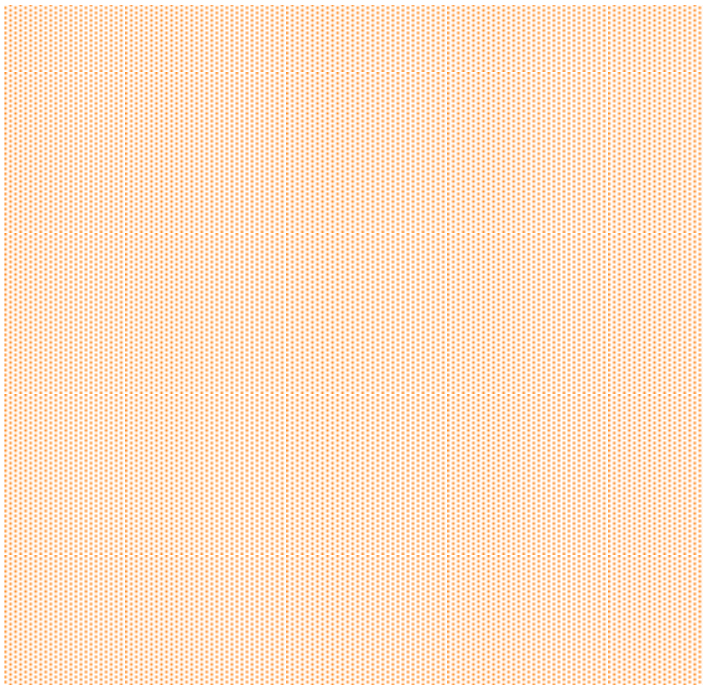

Figure 1. Sketch of the standard AC breakdown oil cup.

\subsection{Lightning Impulse Breakdown Tests}

A consecutive impulse generator $(30 \mathrm{~kJ} / 400 \mathrm{kV})$ was used, and voltage signals measured by a high voltage divider were recorded by a TDS2024C impulse analysis system (Xinyuan Electric, Yangzhou, China), as shown in Figure 2.

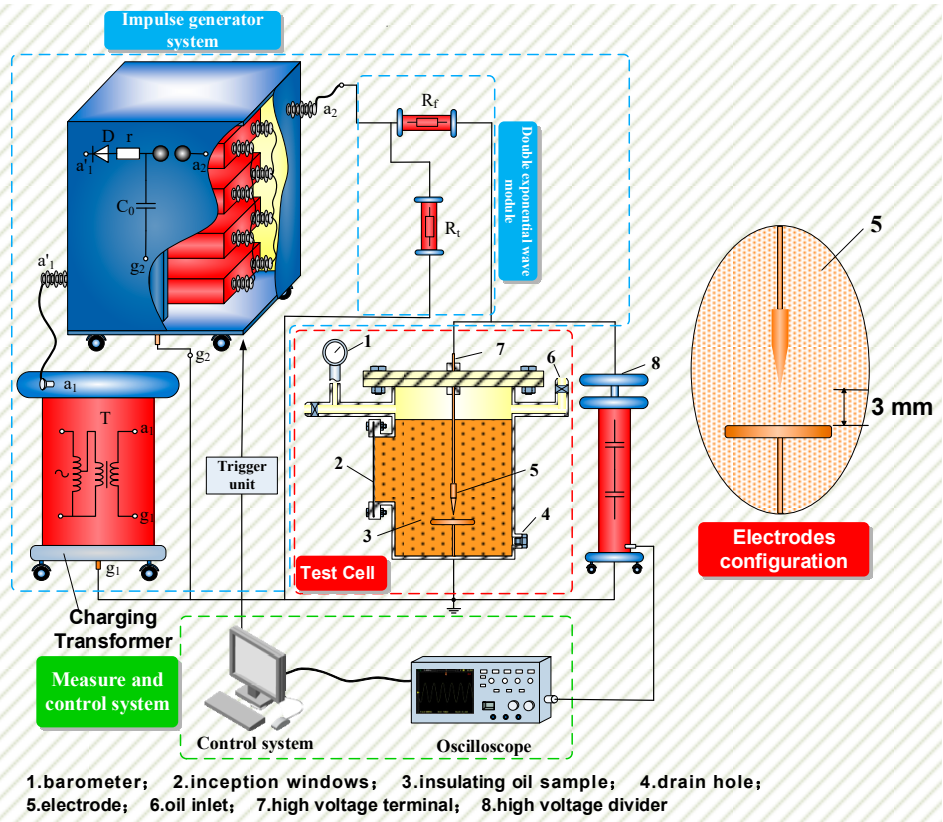

Figure 2. Sketch of the impulse voltage test platform.

The $50 \%$ lightning breakdown voltages (hereinafter referred to as $\mathrm{U}_{50}$ ) of the $\mathrm{FO}$ and $\mathrm{CMIO}$ under positive and negative lightning impulse voltages were obtained through the up-and-down method [27]. Needle-plate electrodes with an oil gap of $3 \mathrm{~mm}$ were used, and the wavefront/tail time of the impulse voltage was $1.2 / 50 \mu \mathrm{s}$. The expected breakdown voltages of the positive and negative impulse breakdown voltages were set at 35 and $46 \mathrm{kV}$, respectively. Applied voltage varies in $1 \mathrm{kV}$ of the expected breakdown voltage, and at least 50 effective shots in total were tested for each sample. The relaxation time between the consecutive shots was $5 \mathrm{~min}$, and the agitation operation lasted for $1 \mathrm{~min}$. 


\subsection{Frequency Domain Dielectric Spectrum Tests}

A Novocontrol Concept 80 Broadband Dielectric Spectrometer (Novocontrol Tech, Montabaur, Germany) was used to measure the dielectric parameters of the FO and CMIO samples. The test frequency in this study ranged from $10^{-2} \mathrm{~Hz}$ to $10^{7} \mathrm{~Hz}$, and the test temperature was set at $30{ }^{\circ} \mathrm{C}$. The temperature accuracy was $\pm 0.01^{\circ} \mathrm{C}$. A calibrating conversion module was adopted to prevent measurement error caused by leakage current.

\subsection{TSC Tests}

The trapping parameters of electrons in dielectric were determined through the TSC technique [28]. The curve plotting the dependence of TSC on temperature can be used in the calculation of trap level and trap density [29]. Figure 3 shows the TSC measurement system we used.
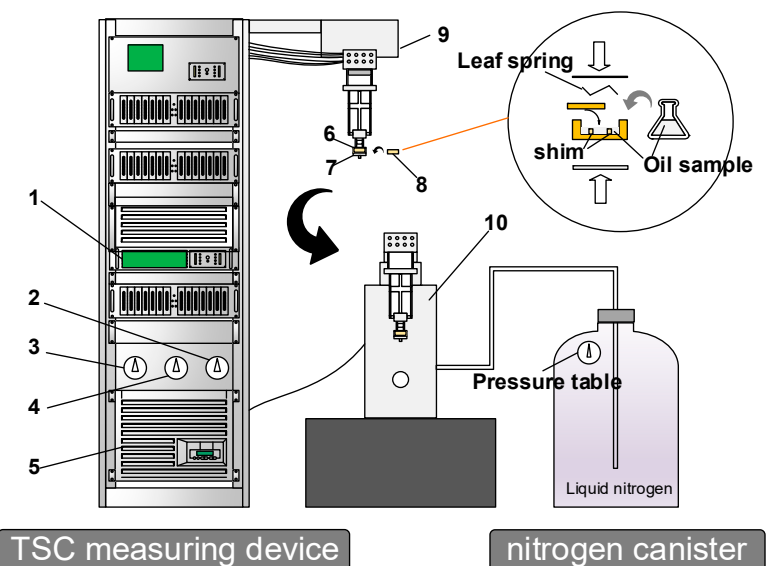

1. TSC calculator; 2. Temperature control system switch; 3. System power switch;

4. TSC calculator switch; 5 . Temperature Control system; 6 . Upper electrode;

7. Lower electrode; 8 . Liquid sample box; 9. Test bench; 10. Test container;

Figure 3. Thermally stimulated current (TSC) measurement system.

During the test, the temperature was adjusted with liquid nitrogen. Data were recorded using LabVIEW software (WinTSC V1.48).

First, the oil sample was added to the sample cell, and a negative DC field of $4 \mathrm{kV} / \mathrm{mm}$ was applied to the tested sample for $30 \mathrm{~min}$ at $323 \mathrm{~K}$. Then, the temperature was lowered to $243 \mathrm{~K}$ at a rate of $10 \mathrm{~K} / \mathrm{min}$ for $15 \mathrm{~min}$. Finally, the sample was heated to $353 \mathrm{~K}$ at a rate of $2 \mathrm{~K} / \mathrm{min}$. The current and sample temperature during the process were recorded.

\subsection{Transmission Electron Microscopy (TEM)}

$\mathrm{C}_{60}$ nanoparticles were examined with a high-resolution transmission electron microscope (HT7700, Hitachi, Japan). The maximum resolution of TEM used in the test was $0.204 \mathrm{~nm}$, and the acceleration voltage was $100 \mathrm{kV}$.

\subsection{Particle Size Distribution and Zeta Potential Tests}

A Malvern Zetasizer Nano ZS90 (Malvern, UK) was used to measure the particle size distribution and zeta potential of the samples. The maximum particle size that the instrument can measure ranges from $5 \mu \mathrm{m}$ to $0.3 \mathrm{~nm}$, and the minimum sample volume for particle size distribution and zeta potential are only 20 and $150 \mu \mathrm{L}$, respectively. 


\section{Results}

\subsection{Zeta Potential and Particle Size Distribution of CMIO}

Electrostatic repulsion among nanoparticles increases at high zeta potential, and this effect signifies good suspension stability [30,31]. Zeta potential test results are related to the $\mathrm{pH}$ and concentration of nanofluids [32,33]. Therefore, for the dispersed particles in insulating oil at $100 \mathrm{mg} / \mathrm{L}$ concentration, measurements were performed with a $633 \mathrm{~nm} \mathrm{He} / \mathrm{Ne}$ laser at a temperature of $25{ }^{\circ} \mathrm{C}$ according to the actual test requirements, so that the requirement of transmittance intensity was satisfied. The refractive index (RI) of $\mathrm{C}_{60}$ particles and insulating oil were set to 1.96 [34] and 1.48, respectively. We selected the test conditions as $\mathrm{pH}=7$, and a total of 12 measurements were taken. The results are shown in Table 3.

Table 3. Zeta potential of nano- $\mathrm{C}_{60}$ modified insulating oil (CMIO) (100 mg/L, $\left.\mathrm{pH}=7\right)$.

\begin{tabular}{cccccccc}
\hline Measurement times & $\mathbf{1}$ & $\mathbf{2}$ & $\mathbf{3}$ & $\mathbf{4}$ & $\mathbf{5}$ & $\mathbf{6}$ & Average value/ $\mathbf{~} \mathbf{V}$ \\
\hline Zeta potential/mV & -43.0 & -40.6 & -41.5 & -39.7 & -38.3 & -45.0 & -41.3 \\
\hline Measurement times & $\mathbf{7}$ & $\mathbf{8}$ & $\mathbf{9}$ & $\mathbf{1 0}$ & $\mathbf{1 1}$ & $\mathbf{1 2}$ & Standard deviation \\
\hline Zeta potential/mV & -45.5 & -41.1 & -41.9 & -39.7 & -38.9 & -41.0 & 2.241 \\
\hline
\end{tabular}

An absolute value of zeta potential greater than $30 \mathrm{mV}$ indicates good dispersion stability [31,35]. Therefore, the CMIO has good dispersion stability.

The particle size distribution of the newly prepared CMIO and the CMIO kept for 12 months were tested. The test results are shown in Figure 4.

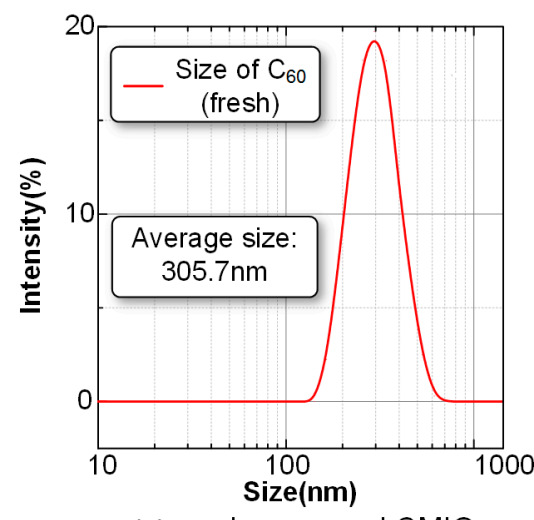

(a) newly prepared $\mathrm{CMIO}$

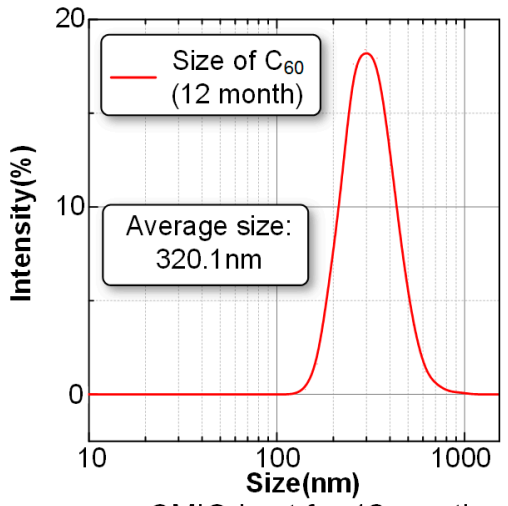

(b) CMIO kept for 12 months

Figure 4. Particle size distribution of nano- $\mathrm{C}_{60}$ particles in $\mathrm{CMIO}$. (a) newly prepared $\mathrm{CMIO}$, (b) CMIO kept for 12 months. (Please note that whether a particle larger than $100 \mathrm{~nm}$ can be called a nanoparticle is still controversial.).

Figure 4 shows that the particle size distribution of the $\mathrm{C}_{60}$ particles in the newly prepared $\mathrm{CMIO}$ is mainly concentrated around $300 \mathrm{~nm}$, and 19.7\% of the particles have diameters of 290-295 nm. The particle size distribution of CMIO kept for 12 months is also concentrated around $300 \mathrm{~nm}$, in which particles with a size of 290-295 nm account for 18.4\%. The average particle size of the newly prepared $\mathrm{CMIO}$ is $305.7 \mathrm{~nm}$, whereas the average particle size of the CMIO kept for 12 months is $320.1 \mathrm{~nm}$.

Notably, surface modifiers were not used for the $\mathrm{C}_{60}$ nanoparticles. However, the particle size of CMIO kept for 12 months showed no significant change. This phenomenon is due to the fact that $\mathrm{C}_{60}$ can dissolve in insulating oil. It should be noted that although the CMIO was stable, the observation period was limited; we will focus on this stability over a longer period. Moreover, aging is a problem faced by transformer oil, and the effect of aging on the solubility and stability of $\mathrm{C}_{60}$ nanoparticles in transformer oil remains to be further studied. 


\subsection{Micromorphology of Nano- $\mathrm{C}_{60}$}

We suspended $\mathrm{C}_{60}$ particles in absolute ethyl alcohol and dripped the mixture onto an ultra-thin carbon mesh. The internal morphology of the sample on ultra-thin carbon mesh was observed by TEM after the alcohol had completely volatilized. The test results are shown in Figure 5 . The $\mathrm{C}_{60}$ nanoparticles are round, and the diameters of most particles are less than $30 \mathrm{~nm}$.

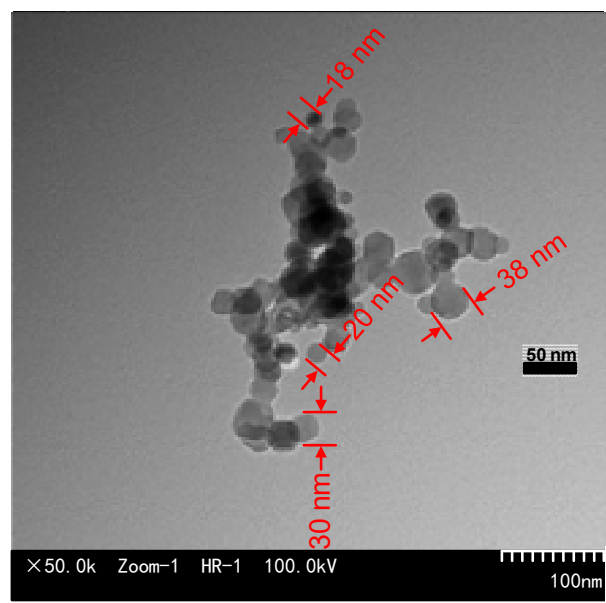

Figure 5. TEM image of the nano- $\mathrm{C}_{60}$ particles.

The particle sizes of the $\mathrm{C}_{60}$ nanoparticles suspended in CMIO increase compared with the particle sizes of the $C_{60}$ nanoparticles in Figure 5. This increase indicates that some $C_{60}$ nanoparticles conglomerated during the preparation process, possibly because no surface modifiers were applied to the $\mathrm{C}_{60}$ nanoparticles. However, $\mathrm{CMIO}$ without surface modifiers still shows good stability.

\subsection{Breakdown Characteristics of FO and $\mathrm{CMIO}$}

In this study, we used the standard lightning impulse wave of positive and negative polarity to determine the breakdown performance of FO and CMIO. The test results are plotted in Figure 6.

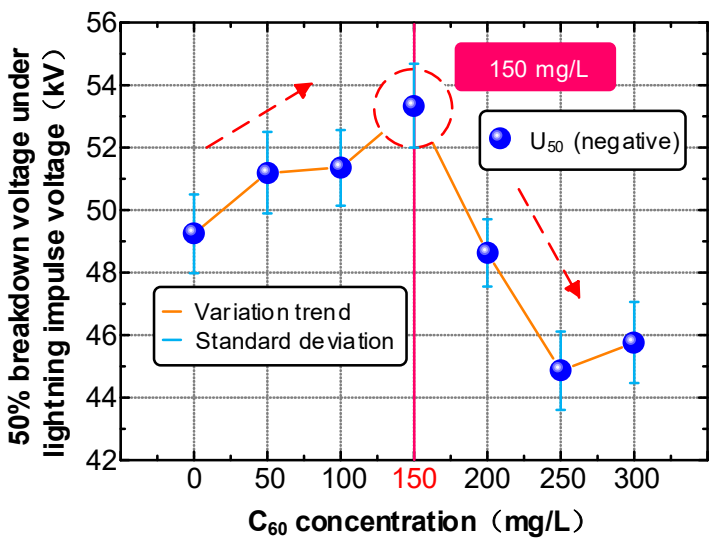

(a) $\cup_{50}$ for negative lightning impulse

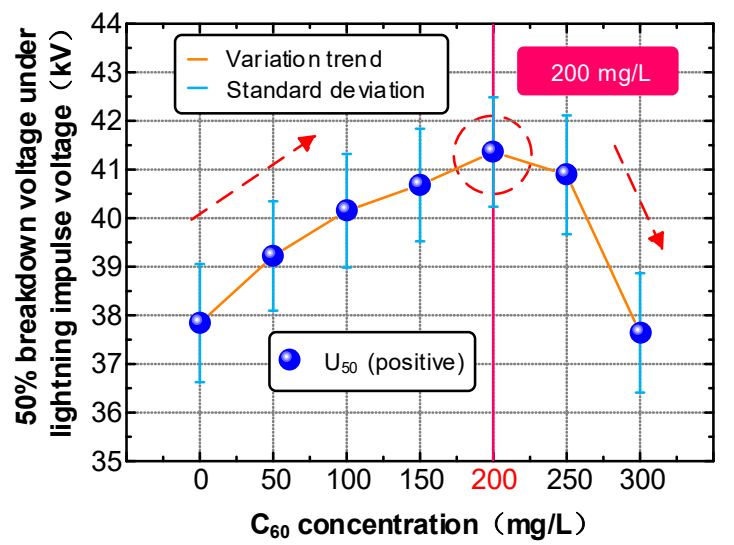

(b) $\cup_{50}$ for positive lightning impulse

Figure 6. Lightning breakdown characteristics of $\mathrm{CMIO}$ and FO. (a) $\mathrm{U}_{50}$ for negative lightning impulse, (b) $\mathrm{U}_{50}$ for positive lightning impulse.

The $\mathrm{C}_{60}$ nanoparticles have a positive influence on the impulse breakdown performance of insulating oil, as can be observed in Figure 6. The positive and negative lightning impulse breakdown voltages of CMIO are simultaneously improved. This improvement in negative lightning impulse breakdown voltage was not observed from the traditional nanoparticle modified insulating oil we 
mentioned before. As shown in Figure 6a, the negative lightning impulse breakdown voltage tends to increase first, then decrease with increasing $\mathrm{C}_{60}$ concentration. However, when the concentration is $300 \mathrm{mg} / \mathrm{L}$, the negative lightning impulse breakdown voltage has a small recovery. The breakdown voltage peaks at $150 \mathrm{mg} / \mathrm{L}\left(\mathrm{U}_{50}=54.23 \mathrm{kV}\right)$. The positive lightning impulse breakdown voltage also increases first, then decreases with increasing $\mathrm{C}_{60}$ concentration, as shown in Figure $6 \mathrm{~b}$. Breakdown voltage reaches its peak value $\left(\mathrm{U}_{50}=41.36 \mathrm{kV}\right)$ at $200 \mathrm{mg} / \mathrm{L} \mathrm{C}_{60}$ concentration. The breakdown voltage drops sharply after at $250 \mathrm{mg} / \mathrm{L} \mathrm{C}_{60}$ concentration, and the positive lightning impulse breakdown voltage is already lower compared with that of $\mathrm{FO}$ at $300 \mathrm{mg} / \mathrm{L}$.

The positive and negative lightning impulse breakdown voltage of CMIO increase by $7.51 \%$ and $8.33 \%$ at $150 \mathrm{mg} / \mathrm{L}$ relative to those of FO. The positive lightning impulse breakdown voltage of CMIO increase by $9.30 \%$, but the negative lightning impulse breakdown voltage decreases by $1.24 \%$ at $200 \mathrm{mg} / \mathrm{L} \mathrm{C}_{60}$ concentration. Therefore, the optimum concentration of CMIO for improving lightning impulse breakdown performance is $150 \mathrm{mg} / \mathrm{L}$.

The average $\mathrm{AC}(50 \mathrm{~Hz})$ breakdown voltage of $\mathrm{CMIO}$ and $\mathrm{FO}$ at different concentrations were further measured. The test results are shown in Figure 7.

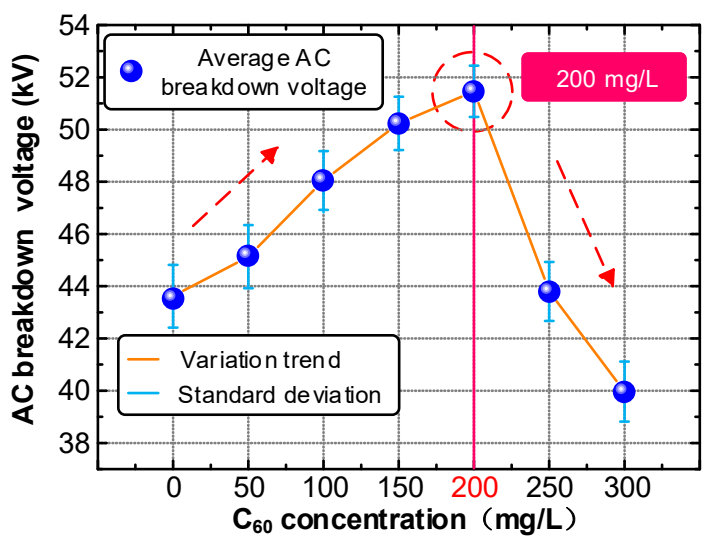

Figure 7. AC breakdown characteristics of $\mathrm{CMIO}$ and fresh oil (FO).

The test results show that the average AC breakdown voltage of CMIO increases at first, then decreases with increasing $\mathrm{C}_{60}$ concentration. The $\mathrm{AC}$ average breakdown voltage reaches its peak (18.0\% higher compared with FO) at $200 \mathrm{mg} / \mathrm{L}$ concentration. The average AC breakdown voltage decreases sharply at $\mathrm{C}_{60}$ concentrations between 200 and $250 \mathrm{mg} / \mathrm{L}$. At $250 \mathrm{mg} / \mathrm{L} \mathrm{C}_{60}$ concentration, the $\mathrm{AC}$ breakdown voltage is slightly higher than that of FO. The lowest average AC breakdown voltage is observed at $300 \mathrm{mg} / \mathrm{L} \mathrm{C}_{60}$ concentration. Considering the results of the lightning impulse breakdown voltage test, we can conclude that the optimum modification concentration of CMIO is $150 \mathrm{mg} / \mathrm{L}$.

\subsection{Dielectric Characteristics of FO and CMIO}

The influence of $\mathrm{C}_{60}$ nanoparticles on the dielectric properties of insulating oil was investigated by measuring the dielectric constants of $\mathrm{CMIO}$ samples with different concentrations at different frequencies, as shown in Figure 8.

The relative dielectric constants of $\mathrm{FO}$ and $\mathrm{CMIO}$ have minimal changes at testing frequencies ranging from $10 \mathrm{~Hz}$ to $10^{7} \mathrm{~Hz}$. The relative dielectric constant of $\mathrm{FO}$ is 2.35 , whereas the relative dielectric constants of CMIO (50-300 mg/L) are 2.37, 2.40, 2.41, 2.42, 2.45, and 2.57 at $50 \mathrm{~Hz}$. The relative dielectric constants of $\mathrm{CMIO}$ and $\mathrm{FO}$ increase sharply with the decrease of test frequency in the range of $0.01-10 \mathrm{~Hz}$. Notably, the dielectric constant of CMIO is slightly higher than that of FO across the entire testing frequency range. 


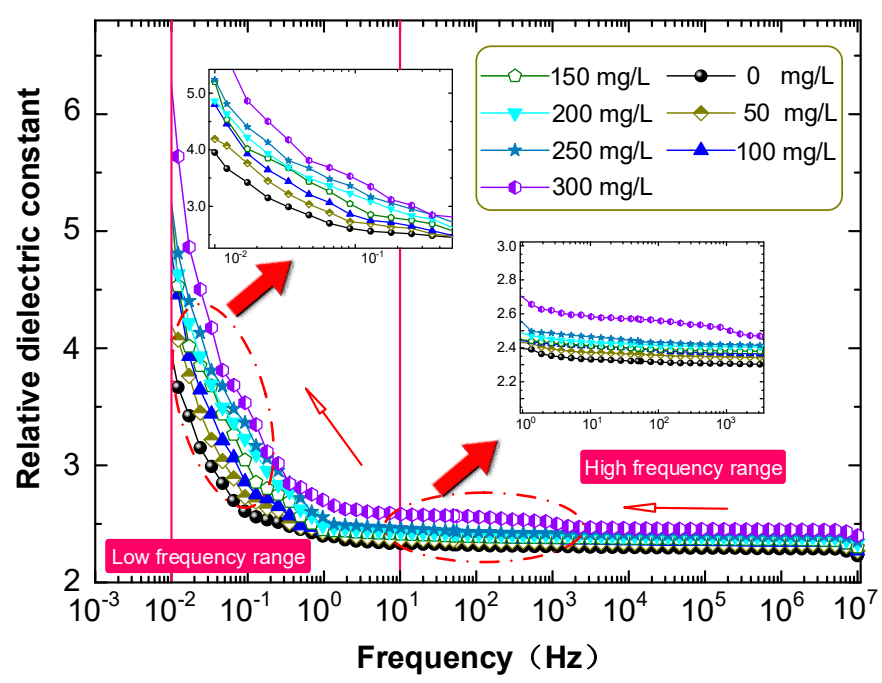

Figure 8. Broadband dielectric spectrum of CMIO and FO.

Transformer insulating oil is nonpolar dielectric and its relative dielectric constant is about 2.2. The polarization equation of nonpolar liquid medium can be expressed as [36]:

$$
\frac{\varepsilon_{r}-1}{\varepsilon_{r}+2}=\frac{N \alpha}{3 \varepsilon_{0}}
$$

where $\varepsilon_{r}$ is the relative dielectric constant of dielectrics, $N$ is the number of molecules per unit volume, $\varepsilon_{0}$ is the vacuum dielectric constant, and $\alpha$ is the total micro-polarizability of molecule. In nonpolar dielectrics, $\alpha$ is the electron displacement polarizability $\alpha_{e}$.

$\mathrm{C}_{60}$ is a nonpolar molecule, and its static dielectric constant is approximately 3.61 [22]. The high frequency dielectric constant of $\mathrm{C}_{60}$ is $2.6 \pm 0.1$ [37]. The solid-liquid system composed of $\mathrm{C}_{60}$ and insulating oil can be treated as nonpolar dielectric, and Equation (1) can be rewritten as:

$$
\frac{\varepsilon_{r}-1}{\varepsilon_{r}+2}=\frac{C_{B} \alpha_{e}}{3 \varepsilon_{0}}
$$

where $C_{B}$ is the molecule number per unit volume of dielectric, and $\alpha_{e}$ is the electron displacement polarizability.

Assuming that $C_{o i l}$ is the molecule number of oil per unit volume of $\mathrm{CMIO}$ and $C_{\mathrm{C} 60}$ is the molecule number of $\mathrm{C}_{60}$ per unit volume of $\mathrm{CMIO}$, Equation (2) becomes:

$$
\frac{\varepsilon_{r}-1}{\varepsilon_{r}+2}=\frac{C_{o i l} \cdot \alpha_{e 1}+C_{C_{60}} \cdot \alpha_{e 2}}{3 \varepsilon_{0}}
$$

where $\alpha_{e 1}$ is the electron displacement polarizability of the oil molecule, and $\alpha_{e 2}$ is the electron displacement polarizability of the $\mathrm{C}_{60}$ molecule.

The relative dielectric constant of $\mathrm{C}_{60}$ is larger than that of insulating oil, so $\alpha_{e 2}>\alpha_{e 1}$. The number of molecules of solids is greater than the number of molecules of liquids in the same volume. Therefore, according to Equation (3), the relative dielectric constants of all the CMIO samples are greater than dielectric constant of FO, and the relative dielectric constant of $\mathrm{CMIO}$ increases with concentration. This result is consistent with the test results shown in Figure 8.

The dielectric loss factor of FO and CMIO with different concentrations at different frequencies were measured, as shown in Figure 9. 


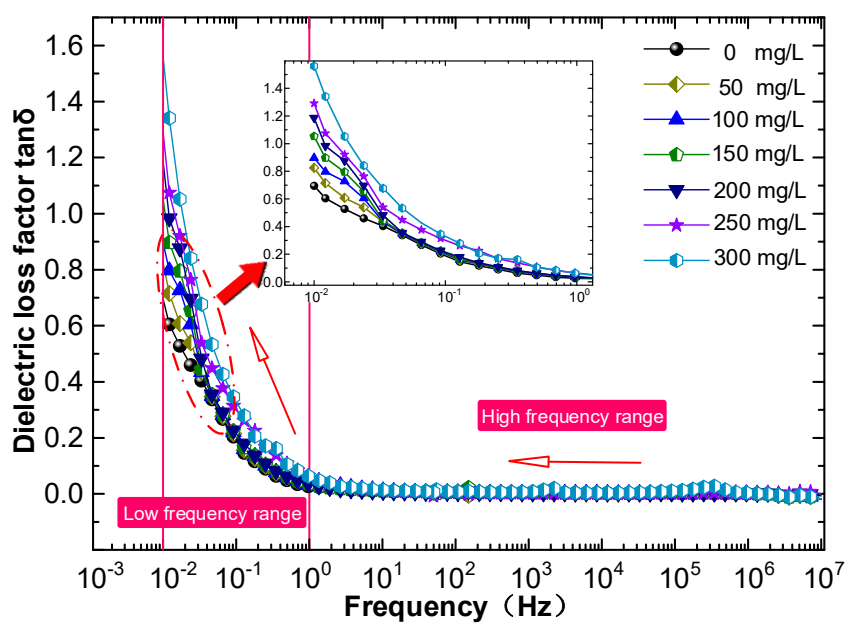

Figure 9. Broadband dielectric loss spectrum of CMIO and FO.

The results show that the $\tan \delta$ of CMIO is almost the same as that of FO from $1 \mathrm{~Hz}$ to $10^{7} \mathrm{~Hz}$. At power frequency $(50 \mathrm{~Hz})$, the $\tan \delta$ of $\mathrm{FO}$ is 0.00537 , and the $\tan \delta$ of CMIO with increasing concentrations $(50-300 \mathrm{mg} / \mathrm{L}$ ) is $0.00548,0.00559,0.00568,0.00651,0.00741$, and 0.00843 .

In the low frequency range (less than $1 \mathrm{~Hz}$ ), the $\tan \delta$ of CMIO is slightly higher than that of FO. The $\tan \delta$ of all the samples increase with decreasing frequency.

The $\tan \delta$ of dielectrics can be expressed as:

$$
\tan \delta=\frac{I_{p}}{I_{q}}=\frac{(\gamma+g) \cdot S E}{\omega \varepsilon_{0} \varepsilon_{r} S E}=\frac{\gamma+g}{\omega \varepsilon_{0} \varepsilon_{r}}
$$

where $I_{p}$ is active current, $I_{q}$ is reactive current, $S$ is cross-sectional area, $E$ is the effective value of electric field strength, $\gamma$ is dielectric conductivity, $g$ is relaxation polarization equivalent conductivity, and $\omega$ is angular frequency.

Electron displacement polarization is the main polarization form of nonpolar and weak polar liquid dielectrics. Their dielectric loss is mainly due to conductivity loss. Relaxation polarization loss can be neglected. The dielectric loss factor in Equation (4) can be rewritten as follows:

$$
\tan \delta=\frac{\gamma}{\omega \varepsilon_{0} \varepsilon_{\mathrm{r}}}
$$

In nonpolar dielectric, the relative dielectric constant barely changes with frequency. The relative dielectric constant increases slightly at a low frequency (less than $1 \mathrm{~Hz}$ ). The dielectric conductivity of insulating oil varies little with frequency, and any change is considered negligible.

According to Equation (5), when changes in $\gamma$ and $\varepsilon_{r}$ are not considered, the tan $\delta$ is approximately an inverse proportional function of the angular frequency $\omega$, which corresponds to the trend of tan $\delta$ with frequency in Figure 9.

$\mathrm{C}_{60}$ is a semiconductor and has greater electrical conductivity than insulating oil. Therefore, the conductivity of CMIO improves and increases with concentration. According to Equation (5), the tan $\delta$ of CMIO is greater than that of FO. The $\tan \delta$ value increases with concentration, and this result is consistent with the test results.

\section{Analysis and Discussion}

\subsection{Trap Characteristics}

The thermal stimulation currents of CMIO and FO were tested with the TSC test system. The test results are shown in Figure 10. 


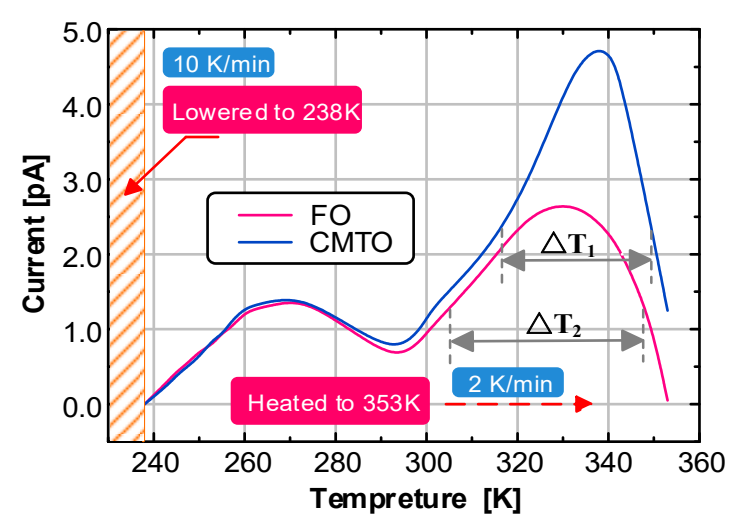

Figure 10. TSC test results of FO and CMIO.

To obtain accurate trap parameters and fit the TSC curve and separate peaks, we used a TSC synthesis algorithm and combined relaxation and thermal excitation process methods.

First, the thermal excitation process was described by the general dynamic equation [38] shown in Equation (6):

$$
I(t)=-\frac{d n}{d t}=\left(\frac{n}{n_{0}}\right)^{b} s n_{0} \exp \left(-\frac{E}{k T}\right)
$$

where $I$ is the heat release intensity in A, which corresponds to the thermal luminescence intensity or the thermal stimulated current intensity. $n$ is the carrier concentration of the trap in $\mathrm{m}^{-3}, s$ is the frequency factor, $n_{0}$ is the initial concentration of carriers of the trap in $\mathrm{m}^{-3}, E$ is the activation energy (trap level) in $\mathrm{eV}, k$ is the Boltzmann constant in $\mathrm{eV} / \mathrm{K}, T$ is the absolute temperature in $\mathrm{K}$, and $b$ is the kinetic order. Usually, $b$ only takes 1,2 , and 1.5 [39].

The solution of Equation (6) is:

$$
\begin{gathered}
I(T)=n_{0} s \exp \left(-\frac{E}{k T}\right) \exp \left(-\frac{s}{\beta} \int_{T_{0}}^{T} e^{-\frac{E}{k T^{\prime}}} d T^{\prime}\right)(b=1) \\
\left.I(T)=n_{0} \exp \left(-\frac{E}{k T}\right)\left[1+(b-1) \frac{s}{\beta} \int_{T_{0}}^{T} e^{-\frac{E}{k T^{\prime}}} d T^{\prime}\right)\right]^{\frac{b}{1-b}}(b \neq 1)
\end{gathered}
$$

where $T_{0}$ is the initial temperature in $\mathrm{K}$.

If a linear temperature rise process exists, that is, $T=T_{0}+\beta t$, then at the peak of curve $I(T)$

$$
\begin{gathered}
\frac{\beta E}{k T_{m}^{2}}=s e^{-\frac{E}{k T_{m}}}(b=1) \\
1+\frac{(b-1) s}{\beta} \int_{T_{0}}^{T_{m}} e-\frac{E}{k T^{\prime}} d T^{\prime}=\frac{b s k T_{m}^{2}}{\beta} e^{-\frac{E}{k T_{m}}}(b \neq 1)
\end{gathered}
$$

where $T_{m}$ is the temperature corresponding to the peak current in $\mathrm{K}$.

After calculating the logarithm of the two sides of Equation (6), we obtained the following equation:

$$
\ln I(t)=b \ln \left(\frac{n}{n_{0}}\right)+\ln \left(s n_{0}\right)-\frac{E}{k T}
$$

After points $\left(T_{1}, I_{1}\right)$ and $\left(T_{2}, I_{2}\right)$ on the TSC curve were substituted into Equation (11),

$$
\ln \left(\frac{I_{2}}{I_{1}}\right)=b \ln \left(\frac{n_{2}}{n_{1}}\right)-\frac{E}{k}\left(\frac{1}{T_{2}}-\frac{1}{T_{1}}\right)
$$


Then, using the two points $\left(T_{3}, I_{3}\right)$ and $\left(T_{1}, I_{1}\right)$ on the TSC curve, we obtained:

$$
\ln \left(\frac{I_{3}}{I_{1}}\right)=b \ln \left(\frac{n_{3}}{n_{1}}\right)-\frac{E}{k}\left(\frac{1}{T_{3}}-\frac{1}{T_{1}}\right)
$$

After Equations (12) and (13) were combined, the activation energy (trap level) and kinetic progression were calculated by:

$$
\begin{gathered}
E=\frac{k\left[\ln \left(\frac{I_{3}}{I_{1}}\right) \ln \frac{n_{2}}{n_{1}}-\ln \left(\frac{I_{2}}{I_{1}}\right) \ln \frac{n_{3}}{n_{1}}\right]}{\left[\left(\frac{1}{T_{2}}-\frac{1}{T_{1}}\right) \ln \left(\frac{n_{3}}{n_{1}}\right)-\left(\frac{1}{T_{3}}-\frac{1}{T_{1}}\right) \ln \left(\frac{n_{2}}{n_{1}}\right)\right]} \\
b=\left[\ln \left(\frac{I_{2}}{I_{1}}\right)+\frac{E}{k}\left(\frac{1}{T_{2}}-\frac{1}{T_{1}}\right)\right] / \ln \left(\frac{n_{2}}{n_{1}}\right)
\end{gathered}
$$

In simple TSC curves (isolated peak), provided that three points $\left(I_{1}, T_{1}\right),\left(I_{2}, T_{2}\right)$, and $\left(I_{3}, T_{3}\right)$ are selected on the curves, $E$ and $b$ can be calculated according to Equations (14) and (15), and $s$ can be calculated from Equations (9) and (10). Meanwhile, $n$ can be calculated by:

$$
n=\frac{1}{\beta} \int_{T}^{T \infty} I d T^{\prime}
$$

where $T_{\infty}$ is the temperature at which the TSC curve decays to zero (actually below the sensitivity of the meter).

For the calculation of $\int_{T_{0}}^{T_{m}} e^{-\frac{E}{k T^{\prime}}} d T^{\prime}$ in Equation (10), the Gaussian quadrature formula can be used. For the $\int_{T}^{T \infty} I d T^{\prime}$ in Equation (16), the following method can be used. First, a point is taken every $1 \mathrm{~K}$ on the TSC curve, and the curve is discretized into $N$ points. Then, by using the $N$ points as interpolation points, cubic spline interpolation is carried out and the TSC curve is expressed by piecewise cubic spline function, so the integral in Equation (16) can be transformed into the integral of cubic spline function [40].

However, in actual experimental conditions and results, completely applying the algorithm is difficult. The current of most samples in the actual measurement were attenuated to zero before the end of the TSC measurement given the limitation of the temperature tolerance of the heater. Therefore, we failed to calculate $n$ by using Equation (16).

Another drawback of the thermal excitation process is that the trap level $E$ calculated from the multipoint values on the actual curve vary greatly in some cases. Therefore, we had to use the relaxation process method to obtain the preliminary theoretical curve of the measured TSC.

The activation energy (trap level) $E$ can be calculated by the half-width formula [41]:

$$
E=\frac{2.47 T_{m}^{2} k}{\Delta T}
$$

where $\Delta T$ is the temperature difference corresponding to the half-peak in $\mathrm{K}$, and $k$ is the Boltzmann constant in $\mathrm{eV} / \mathrm{K}$.

Assuming that the measured TSC curve is a single frequency relaxation process, according to Debye theory, the short circuit TSC can be expressed as [28]:

$$
I=A \exp \left[-\frac{E}{k T}-\frac{1}{\tau_{0} \beta} \int_{T_{0}}^{T} \exp \left(-\frac{E}{k T}\right) d T\right]
$$

where $\tau_{0}$ is the time constant, and $\beta$ is the heating rate in $\mathrm{K} / \mathrm{min}$.

The relationship between $I$ and $T$ can be calculated by using Equation (18) combined with the TSC curve. 
Using the Gorbachev approximation,

$$
\begin{gathered}
\int_{T_{0}}^{T} \exp \left(-\frac{E}{k T}\right) d T=\int_{0}^{T} \exp \left(-\frac{E}{k T}\right) d T-\int_{0}^{T_{0}} \exp \left(-\frac{E}{k T}\right) d T \\
\quad=\int_{0}^{T} \exp \left(-\frac{E}{k T}\right) d T+C \approx\left(\frac{k T^{2}}{E+k T}\right) \exp \left(-\frac{E}{k T}\right)+C
\end{gathered}
$$

$C$ in Equation (19) is a constant independent of $T$, so

$$
I \approx A \exp \left[-\frac{E}{k T}-\frac{1}{\tau_{0} \beta}\left(\frac{k T^{2}}{2 k T+E}\right) \exp \left(-\frac{E}{k T}\right)-\frac{C}{\tau_{0} \beta}\right]
$$

Make $\frac{d I}{d T}=0$, get

$$
\tau_{0} \beta \approx \frac{k T^{2}}{E}\left[\frac{E}{E+2 k T} \exp \left(-\frac{E}{k T}\right)+\frac{2 k T}{E+2 k T} \exp \left(-\frac{E}{k T}\right)\right]=\frac{k T^{2}}{E} \exp \left(-\frac{E}{k T}\right)
$$

$\frac{d I}{d T}=0$ corresponds to $I_{\mathrm{m}}, T_{\mathrm{m}}$ in the TSC spectrum, substituting $I_{\mathrm{m}}$ and $T_{\mathrm{m}}$ into Equation (21).

$$
\tau_{0} \beta \approx \frac{k T_{m}^{2}}{E} \exp \left(-\frac{E}{k T_{m}}\right)
$$

From Equation (20), we can obtain the following equation:

$$
\begin{gathered}
I_{m} \approx A \exp \left(-\frac{C}{\tau_{0} \beta}\right) \exp \left[-\frac{E}{k T_{m}}-\frac{1}{\tau_{0} \beta}\left(\frac{k T_{m}{ }^{2}}{2 k T_{m}+E}\right) \exp \left(-\frac{E}{k T_{m}}\right)\right] \\
=A^{\prime} \exp \left[-\frac{E}{k T_{m}}-\frac{1}{\tau_{0} \beta}\left(\frac{k T_{m}^{2}}{2 k T_{m}+E}\right) \exp \left(-\frac{E}{k T_{m}}\right)\right]
\end{gathered}
$$

By substituting $I_{\mathrm{m}}$ and $T_{\mathrm{m}}$ into Equation (23), the value of $A^{\prime}$ can be obtained. Then, $A^{\prime}$ and Equations (20), (22), and (23) can be used in the determination of the fitting curve of I-T (TSC curve).

In the relaxation process method, the TSC curve is assumed to be a single relaxation process, and some approximations are made. Therefore, the theoretical curve obtained by this method does not fit the measured curve well but can be used as the basis of the thermal excitation process method.

We substituted the data points selected from the theoretical curve of the relaxation process algorithm into the thermal excitation process algorithm to calculate the corresponding trap parameters. Then, we compared the theoretical curves obtained from these trap parameters with the measured TSC curves and gradually adjusted the trap depth and other trap parameters until the calculated fitting curves were the same as the measured curves. The algorithm which combines the relaxation process method with the thermal excitation process method was called the synthesis algorithm.

The main peak I was fitted first, which is on the right side of the TSC curve. The fitted and actual curves are shown in Figure 11.

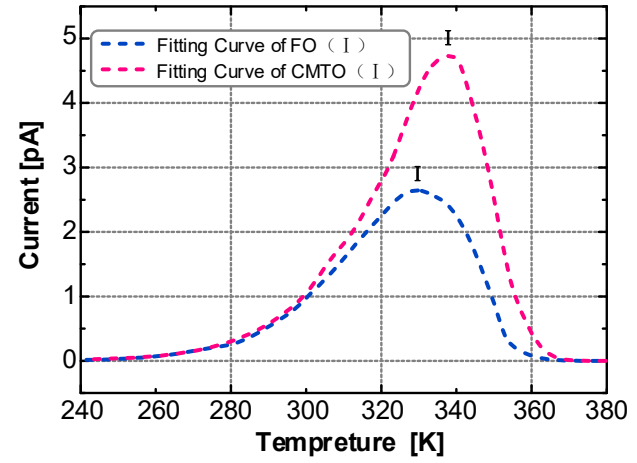

(a)

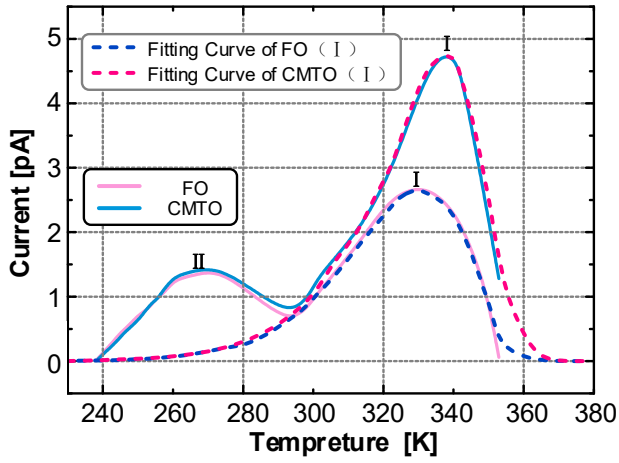

(b)

Figure 11. (a) Peak I fitting curve of FO and $\mathrm{CMIO}$, (b) Comparison of Peak I fitting and measured curves. 
That the TSC curve fitted by the steps has a high degree of coincidence with the actual curve can be seen from Figure 11b. Despite the slight deviation between the fitting and actual curves in the initial and end parts, the remaining parts basically coincide.

The measured TSC curve has two peaks, main peak I and secondary peak II. Peak separation is needed to complete the fitting of the entire TSC curve. The curve measured in the experiment is actually the superposition of main peak I and secondary peak II. After the fitting of main peak I was completed, the measured curve of peak II was obtained by subtracting the fitting curve of main peak I from the measured TSC curve. Then, the synthesis algorithm was used to fit secondary peak II. Finally, we obtained the fitting of the whole measured TSC curve, as shown in Figure 12.

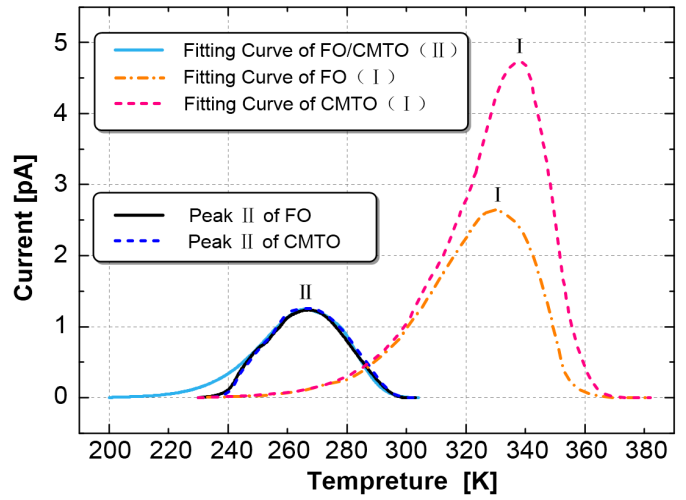

Figure 12. Measured curve of peak II of FO and CMIO and fitting curve of peaks I and II.

As shown in Figures 11 and 12, the curve fitted by the synthetic algorithm has a high overall coincidence with the measured curve, but the curves differ in the initial rising and final falling parts. Moreover, this method can complete the TSC curve fitting including multiple peaks.

Given that the temperature is approximately proportional to time, the integration of the current with temperature can be used in the calculation of the amount of charge released by the trap [41], as shown in the following equation:

$$
Q=\int_{t_{0}}^{t_{1}} I(t) d t=\frac{1}{\delta} \int_{T_{0}}^{T_{1}} I(T) d T
$$

where $Q$ is total charge of the trap in $\mathrm{C}, \delta$ is the heating rate in $\mathrm{K} / \mathrm{min}, T_{0}$ is the experimental starting temperature, and $T_{1}$ is the temperature at which the current drops to zero.

The characteristic values of the TSC trap parameter of the insulating oil can be obtained by fitting and calculating, as shown in Table 4.

Table 4. Characteristics of TSC trap parameters of insulating oil.

\begin{tabular}{clc}
\hline Trap Parameter & FO & CMIO \\
\hline Peak Current (I)/pA & 2.68 & 4.84 \\
Peak Current (II)/pA & 1.25 & 1.25 \\
Trap level (I)/eV & 0.505 & 0.718 \\
Trap level (II)/eV & 0.426 & 0.426 \\
$\mathrm{Q}(\mathrm{I}) / \mathrm{nC}$ & 3.63 & 5.12 \\
$\mathrm{Q}(\mathrm{II}) / \mathrm{nC}$ & 1.30 & 1.30 \\
\hline
\end{tabular}

The peak II trap parameters of FO and CMIO are almost the same. All the traps are shallow with levels of about $0.42 \mathrm{eV}$. Nano- $\mathrm{C}_{60}$ particles do not change the trap characteristics of $\mathrm{CMIO}$ at peak II but mainly affect peak I. At peak I, the peak current of CMIO (4.84 pA) is 1.81 times that of FO (2.68 pA), the trap level of $\mathrm{CMIO}(0.718 \mathrm{eV})$ is 1.42 times that of $\mathrm{FO}(0.505 \mathrm{eV})$, and the trap charge of CMIO 
$(5.12 \mathrm{nC})$ is 1.41 times that of $\mathrm{FO}(3.63 \mathrm{nC})$. Given that the peak value of the TSC curve is related to maximum trap density in a dielectric liquid [28], CMIO is believed to have a higher trap density than FO. Therefore, we infer that the addition of nano- $\mathrm{C}_{60}$ particles increases the trap energy level depth and trap density of insulating oil.

\subsection{Adsorption of Charge Carriers and Percolation Threshold Phenomenon}

Electrical conductivity in an insulation material depends on the amount or concentration of charge carriers $\left(N_{i}\right)$, the charge of charge carriers $\left(q_{i}\right)$, and their mobility $\left(\mu_{i}\right)$, which can be expressed as [42]:

$$
\sigma=\sum_{i} N_{i} q_{i} \mu_{i}
$$

Decreasing the concentration of potential charge carriers by increasing the chemical cleanliness of the insulating material, and reducing their mobility by introducing a filler that contains traps for charge carriers are equally important to the reduction of conductivity [42].

The trap fill effect is not needed at small trap charge [43]. The carrier mobility is shown in Figure 13.

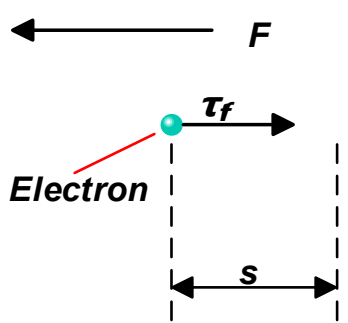

(a)

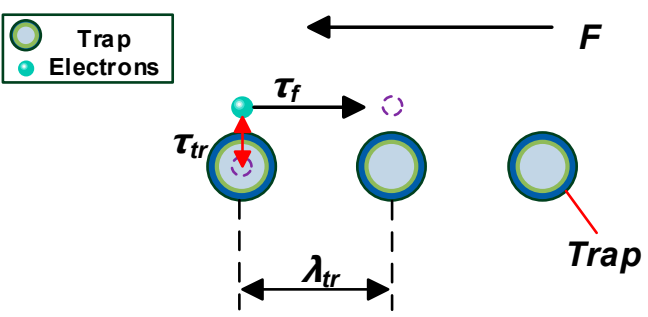

(b)

Figure 13. (a) Carrier migration in the medium (without traps), (b) carrier migration in the medium (with traps).

According to the formula for calculating the mean free path of carriers $\lambda_{f}$ [44]:

$$
\lambda_{f}=\mu_{0} F \cdot \tau_{F}
$$

where $\mu_{0}$ is the carrier mobility when no trap exists in the dielectric material, $F$ is the external electric field, and $\tau_{F}$ is the lifetime of the carrier.

As shown in Figure 13a, when no trap exists in the dielectric material under the action of electric field $F$, the time $\tau_{f}$ required for the $s$ distance of carrier migration can be calculated as follows:

$$
\tau_{f}=\frac{s}{F \cdot \mu_{0}}
$$

When traps exist in dielectric materials (Figure 13b), carriers are trapped. If the carrier resides in the trap for a time of $\tau_{t r}$, the total time $\tau_{t o}$ spent for carrier migration in the $s$ distance is:

$$
\tau_{t o}=\tau_{f}+\tau_{t r}
$$

The effective mobility of carriers can be calculated by [45]:

$$
\mu_{e f}=\frac{\lambda_{t r}}{F \cdot \tau_{t o}}=\frac{\mu_{0} \cdot \tau_{f}}{\tau_{f}+\tau_{t r}}
$$


Generally, the carrier residence time $\tau_{t r}$ in the shallow trap is very short and is shorter than the carrier lifetime $\tau_{f}$. According to Equation (29), the carrier effective mobility $\mu_{e f}$ is approximately equal to the carrier mobility $\mu_{0}$ in the shallow trap. Therefore, after being trapped by shallow traps in the FO, electrons can easily escape again. The frequency of electrons entering the trap is equivalent to the frequency of electrons leaving the trap, and the trapping ability of the shallow trap is weak.

Carrier trapping time in deep traps is generally longer than carrier lifetime [46]. Deep traps form a charge trapping center, which causes space charge accumulation in the dielectric. At this time, carrier effective mobility $\mu_{e f}$ is smaller than carrier mobility $\mu_{0}$.

$\mathrm{CMIO}$ has a deeper trap level and a higher trap density than FO, and the frequency of electrons entering the trap is higher than the frequency of electrons leaving the trap. Moreover, the binding ability of electron trap is strong. Carrier mobility in CMIO is lower than that in FO. Therefore, the number of electrons trapped by the deep and dense traps in CMIO increases during discharge development, and this increase weakens the development of streamers and increases breakdown voltage.

The volume fraction of a conducting filler in an insulating matrix has a critical level, above which the electrical or thermal conductivity increases dramatically due to the development of a continuous path of electron transport [47]. This critical volume fraction, which is the minimum concentration required to create an infinitely connected network, is called the percolation threshold [48]. The resistivity or conductivity near the percolation threshold can then be described by Equation (30) [47,49]:

$$
\sigma \propto\left(v-v_{c}\right)^{t}
$$

where $v$ is the volume fraction of filler, $v_{\mathrm{c}}$ is the percolation threshold, and $t$ is a power law constant that depends on the geometry of the system.

For the reduction of the charge mobility or DC conductivity in composites based on non-insulating particles, the particle volume fraction in the composite system should typically be lower than the percolation threshold, where conduction may occur by tunneling between particles because of short interparticle distance $[50,51]$. At this critical interparticle distance, the trapping of charge carriers by non-insulating particles is not beneficial for conductivity reduction.

The tunneling effect can be described as shown in Figure 14.

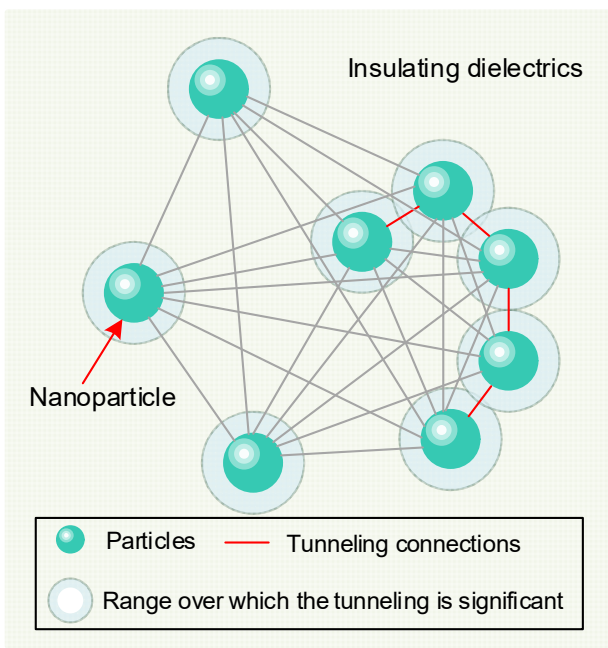

Figure 14. Schematic diagram of tunneling effect.

When the distance between particles is less than the critical interparticle distance (the red line in Figure 14), a system of geometrically disconnected particles occurs. In this system, an insulating layer separates adjacent particles and electrically these are all connected by tunneling [49]. 
In $\mathrm{CMIO}$, the volume fraction of $\mathrm{C}_{60}$ nanoparticles must not exceed the percolation threshold. As observed in our experimental data, the breakdown voltage of CMIO drops sharply at a certain $\mathrm{C}_{60}$ concentration. This sharp drop may be related to the percolation threshold.

\subsection{Relaxation Time Constant and Electrical Potential Distribution of $\mathrm{C}_{60}$ Nanoparticles}

The conductivity of $\mathrm{C}_{60}$ single crystal at room temperature is approximately $1.7 \times 10^{-6} \mathrm{~S} / \mathrm{m}$ [52]. The relaxation time constant of $\mathrm{C}_{60}$ nanoparticles in $\mathrm{CMIO}$ can be calculated by the following equation [53]:

$$
\tau_{r}=\frac{2 \varepsilon_{1}+\varepsilon_{2}}{2 \sigma_{1}+\sigma_{2}}
$$

where $\varepsilon_{1}$ is the relative permittivity of insulating oil $\left(2.2 \varepsilon_{0}\right), \varepsilon_{2}$ is the relative permittivity of $\mathrm{C}_{60}$ nanoparticles $\left(4 \varepsilon_{0}\right), \sigma_{1}$ is the conductivity of insulating oil $\left(10^{-12} \mathrm{~S} / \mathrm{m}\right), \sigma_{2}$ is the conductivity of $\mathrm{C}_{60}$ nanoparticles $\left(1.7 \times 10^{-6} \mathrm{~S} / \mathrm{m}\right)$, and $\varepsilon_{0}$ is the vacuum permittivity $\left(8.85 \times 10^{-12} \mathrm{~F} / \mathrm{m}\right)$.

The relaxation time constant of the $\mathrm{C}_{60}$ nanoparticles in CMIO calculated from Equation (31) is $4.37 \times 10^{-5} \mathrm{~s}$. According to the fast electron capture theory [53], the relaxation time constant $\tau_{r}$ of nanoparticles represents the speed of polarization process of nanoparticles. However, the relaxation time constant of $\mathrm{C}_{60}$ nanoparticles in $\mathrm{CMIO}$ is much larger than the development time of the streamer (the development time range of streamer is from several hundred nanoseconds to several microseconds). Therefore, $\mathrm{C}_{60}$ nanoparticles have other mechanisms which act on the modification of insulating oil.

Transformer insulating oil is a nonpolar dielectric. Few dipoles are present in the filtered and vacuum dried oil samples. However, due to the difference in relative dielectric constant between $\mathrm{C}_{60}$ and insulating oil, nanoparticles generate induced dipole moments under a high electric field [54]. The surface of the nanoparticles will have a charge distribution. The charge distributed on these surfaces will trap the rapidly migrating electrons and hinder the development of streamers.

Assume that $\mathrm{C}_{60}$ nanoparticles in insulating oil is a standard spherical dielectric. The spherical dielectric (diameter $2 a$, relative permittivity $\varepsilon_{2}$ ) is present in the base dielectric material (insulating oil, relative permittivity $\varepsilon_{1}$ ), as shown in Figure $15 \mathrm{~b}$. Figure $15 \mathrm{a}$ is dipole electric charge and the electric line of force distributions near the spherical dielectric induced by an electric field $E_{0}$.

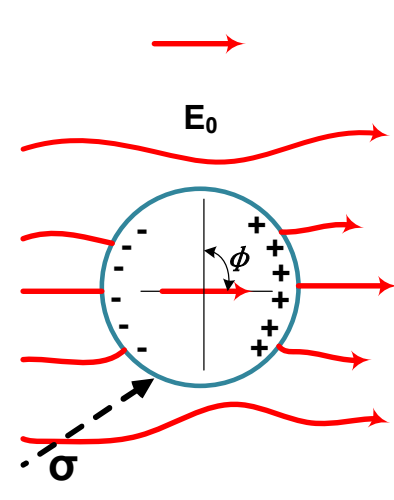

(a)

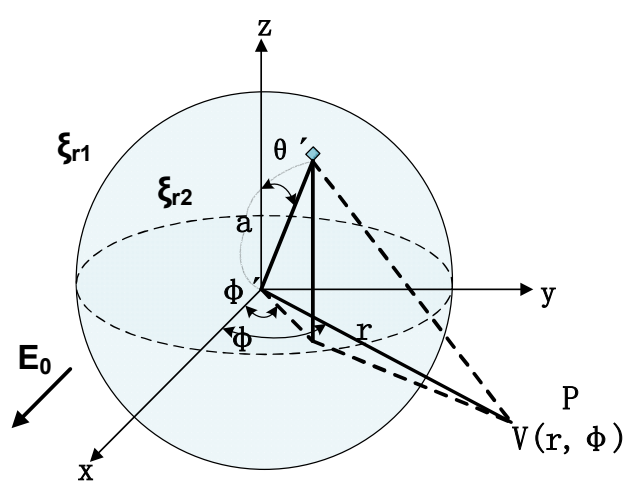

(b)

Figure 15. (a) Dipole electric charge and electric line of force distributions near spherical dielectric induced by an electric field $\mathrm{E}_{0},(\mathbf{b})$ The spherical dielectric is present in the base dielectric material.

The surface charge density $\sigma_{p}$ and electrical potential $V(r, \Phi)$ of the spherical dielectric can be calculated by using Equations (32) and (33):

$$
\sigma_{p}=\varepsilon_{0} E_{0}\left(1-\frac{3 \varepsilon_{r 1}}{2 \varepsilon_{r 1}+\varepsilon_{r 2}}\right) \cos \phi^{\prime} \sin \theta^{\prime}
$$




$$
\frac{V(r, \phi)}{a E_{0}}=\frac{1}{4 \pi}\left[1-\frac{3 \varepsilon_{r 1}}{2 \varepsilon_{r 1}+\varepsilon_{r 2}}\right] \times \int_{-\pi}^{+\pi} \int_{0}^{+\pi} \frac{\sin ^{2} \theta^{\prime} d \theta^{\prime} \cos \phi^{\prime} d \phi^{\prime}}{\sqrt{1+(r / a)^{2}-2(r / a) \sin \theta^{\prime} \cos \left(\phi-\phi^{\prime}\right)}}
$$

According to the TSC test procedure in Section 4.1 Trap Characteristics, the electric field strength $E_{0}=4 \mathrm{kV} / \mathrm{mm}$ applied in the experiment, the relationship between the particle size of $C_{60}$ nanoparticles in CMIO and the electrical potential along the electric field and the central axis can be obtained by using Equations (32) and (33), as shown in Figure 16.

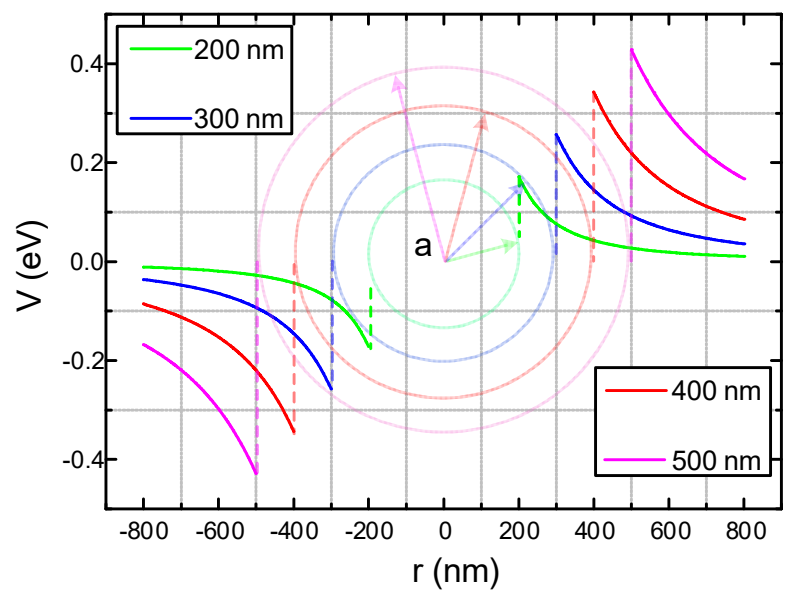

Figure 16. Electrical potential of $C_{60}$ spherical nanoparticles along the electric field $E_{0}$ and central axis.

As shown in Figure 16, under $E_{0}$ of $4 \mathrm{kV} / \mathrm{mm}$, the surface charge potential of a $\mathrm{C}_{60}$ nanoparticle is $0.257 \mathrm{eV}$ when the particle size is $300 \mathrm{~nm}$. The TSC test result shows that the maximum trap level generated by $\mathrm{C}_{60}$ nanoparticles in $\mathrm{CMIO}$ is $0.718 \mathrm{eV}$. When the error of the model itself is excluded, the surface electric potential calculated according to this model is smaller than the trap value actually measured in the TSC test. This difference may be attributed to the following reasons:

- In this model, the applied electric field $E_{0}$ is uniform. In the TSC test, the small shim in the oil tank (Figure 3) affects the uniformity of the electric field distribution.

- The nanoparticles (or nanoparticle agglomerates) are assumed to be standard spheres in this model, and thus their morphology may be different from that of $\mathrm{C}_{60}$ nanoparticles present in CMIO.

- More importantly, we believe that the adsorption of carriers by $\mathrm{C}_{60}$ in $\mathrm{CMIO}$ is not only the effect of the electric potential wells produced by the induced dipole consisting of $\mathrm{C}_{60}$ nanoparticles under a high electric field, but also the electronegativity effect of $C_{60}$. We will further discuss the effect of $\mathrm{C}_{60}$ electronegativity on electron adsorption in Section 4.4.

\subsection{Electronegativity of $\mathrm{C}_{60}$}

$\mathrm{C}_{60}$ nanoparticles have strong "electronegativity" (the ability to capture electrons) and their electronic affinity $E A$ can be expressed by the following equation [18]:

$$
E A=E\left(R_{e}\right)-E^{-}\left(R_{e}^{-}\right)
$$

where $E A$ is the electron affinity, $E\left(R_{e}\right)$ is the total energy of a stable neutral molecule, and $E^{-}\left(R_{e}^{-}\right)$is the total energy of a stable molecule after capturing an electron.

The most accurate electron affinity for $\mathrm{C}_{60}$ is [17]:

$$
E A=2.683 \pm 0.008 \mathrm{eV}
$$


The $E A$ of $\mathrm{C}_{60}$ is higher than the electronic affinity (about $1.06 \mathrm{eV}$ ) of $\mathrm{SF}_{6}$, which is an excellent gas insulation material and has been widely used. Thus, $\mathrm{C}_{60}$ has a strong electron adsorption ability. The capturing effect of $\mathrm{C}_{60}$ added to insulating oil on electrons is shown in Figure 17.

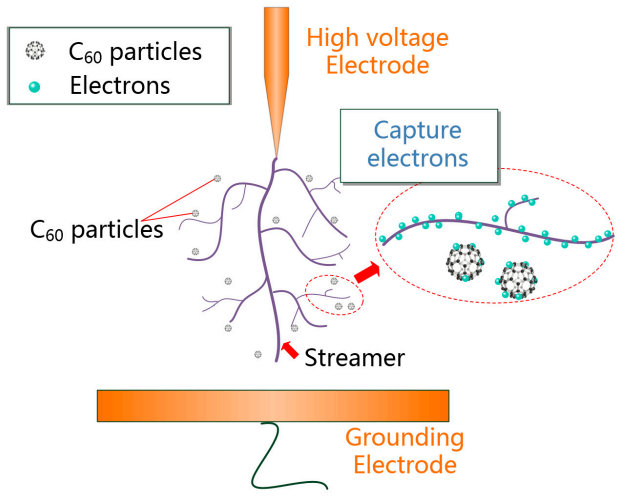

Figure 17. $\mathrm{C}_{60}$ particles capture electrons involved in streamer formation.

$\mathrm{C}_{60}$ nanoparticles can capture electrons which reduces the number of electrons that can participate in the formation of electron avalanches under the action of electric field, thus weakening the development of streamers and increasing the breakdown voltage of CMIO.

The ability of $\mathrm{C}_{60}$ to absorb electrons is caused by its special structure at the microlevel. We suspect that the electron adsorption capacity resulting from the microstructure leads to the deepening of the trap shown in Section 4.1.

\subsection{Absorption of Photons by $C_{60}$}

The photopolymerization of $\mathrm{C}_{60}$ occurs under the irradiation of ultraviolet light or visible light of a specific wavelength. Irradiation results in the polymerization of two adjacent $\mathrm{C}_{60}$ molecules and consumption of photons [20]. The $\mathrm{C}_{60}$ dimer is the most abundant and simple structure in the polymer. The formation process can be explained as shown in Figure 18a.

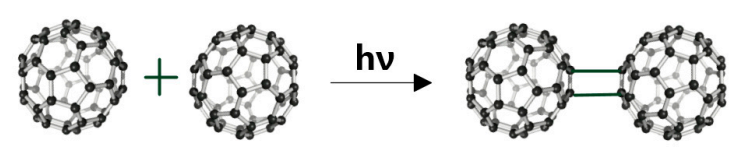

(a)

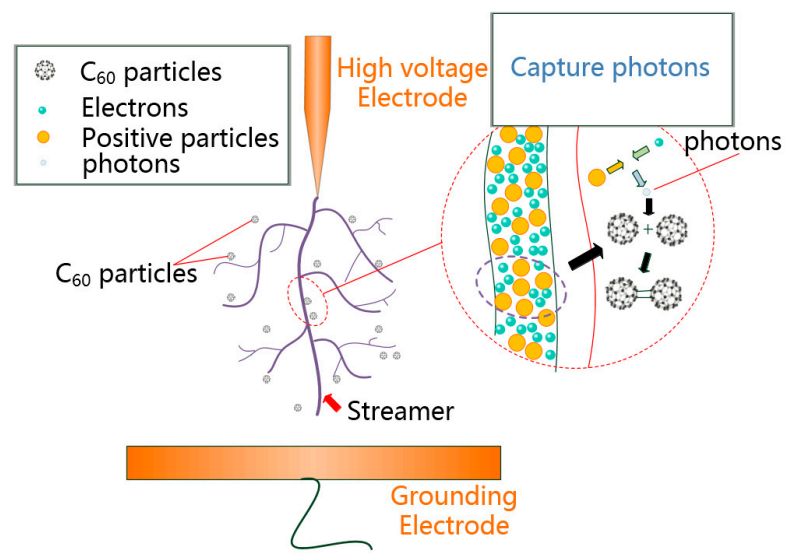

(b)

Figure 18. (a) Two $\mathrm{C}_{60}$ molecules absorb photons and form dimer, (b) $\mathrm{C}_{60}$ absorbs photons in the streamer through photopolymerization reaction. 
As shown in Figure 18b, in the process of streamer development, the positive and negative ions in the electron avalanche recombine violently and emit a large number of photons. These high-energy photons cause subsequent photoionization, thus generating new free electrons (photoelectrons). $\mathrm{C}_{60}$ molecules can absorb photons generated during streamer development through photon absorption polymerization (most are dimers), which weakens the process of photoionization. Thus, the molecules weaken the development of streamers and improve the breakdown performance of CMIO.

We speculate that $\mathrm{C}_{60}$ can improve the negative impulse breakdown voltage of insulating oil because $\mathrm{C}_{60}$ can absorb photons. An explanation for the negative impulse breakdown voltage drop of nano-insulating oil is as follows. A large number of negatively charged slow nanoparticles remain near the negative electrode. This phenomenon weakens the electric field strength at the needle electrode and strengthens it at the plate electrode. Therefore, the enhancement of voltage is conducive to the initiation and development of streamers to the anode and decreases negative breakdown voltages with the suspension of nanoparticles [6].

According to this explanation, the negative impulse breakdown voltage of CMIO should be lower compared with that of FO. However, unlike other nanoparticles, the $\mathrm{C}_{60}$ in $\mathrm{CMIO}$ can absorb photons, weakens the process of photoionization, and disrupts the development of streamers. Therefore, we believe that the absorption of photons by $\mathrm{C}_{60}$ is the reason that $\mathrm{C}_{60}$ can increase the negative impulse breakdown voltage of CMIO, and this factor is what makes CMIO markedly different from other nano-insulating oils.

\subsection{Summary of the Mechanism of $\mathrm{C}_{60}$}

In the development of discharge in $\mathrm{FO}$ and $\mathrm{CMIO}$, the motion of electrons can be represented by Figure 19a,b. The trap parameters of insulating oil, and the electron adsorption capacity of $\mathrm{C}_{60}$, and its ability to absorb photons, affect the breakdown performance of nano-insulating oil and the development process of discharging.

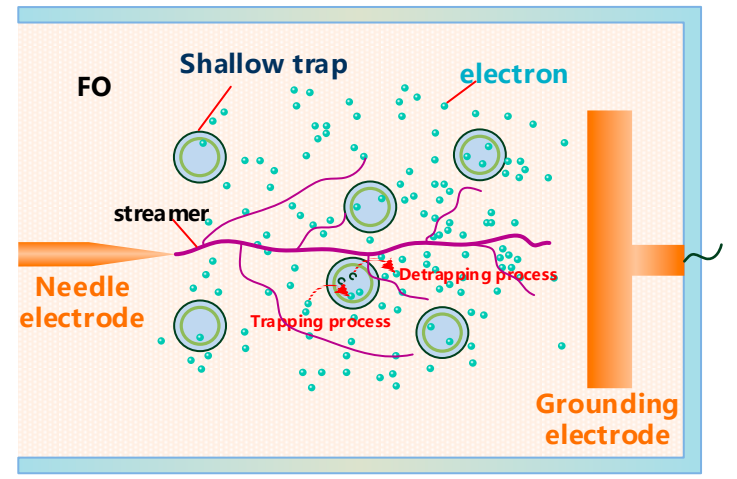

(a)

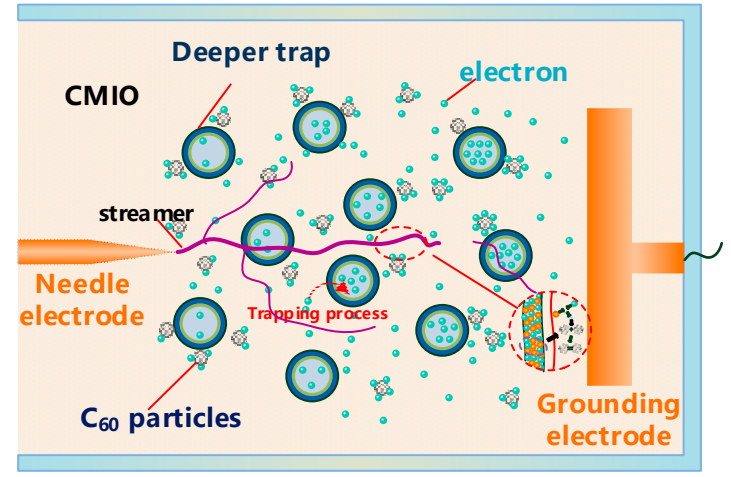

(b)

Figure 19. (a) Electron motion in FO under electric field, (b) Electron motion in CMIO under electric field.

As shown in Figure 19, the modification mechanism of $\mathrm{C}_{60}$ to improve the breakdown performance of insulating oil can be summarized by three aspects:

- The addition of $\mathrm{C}_{60}$ nanoparticles deepens the trap energy level and increases the trap density in insulating oil. In $\mathrm{CMIO}$, the frequency of electrons entering the trap is higher than the frequency of electrons leaving the trap, and the capture ability of the electron trap is strong. Carrier mobility in $\mathrm{CMIO}$ is lower than that in FO. The number of electrons trapped by the deep and dense traps increases.

- $\mathrm{C}_{60}$ nanoparticles have a strong ability to absorb electrons. As $\mathrm{C}_{60}$ captures electrons, it reduces the number of electrons that can participate in the formation of electron avalanches under an electric field, thus weakening the development of streamers and increasing the breakdown voltage of CMIO. 
- $\mathrm{C}_{60}$ molecules can absorb photons generated in the process of streamer development though photon absorption polymerization (most are dimers), which weakens the process of photoionization, and thus disrupts the development of streamers and improves the breakdown performance of CMIO. We believe that the absorption of photons by $\mathrm{C}_{60}$ is the reason for the improvement in the negative impulse breakdown performance of CMIO.

$\mathrm{C}_{60}$ can improve the breakdown performance of insulating oil while hardly increasing dielectric loss. The slight increase in CMIO relative dielectric constant is also beneficial to the insulation coordination of the transformer oil-paper insulation system. However, it should also be noted that due to the cost of $\mathrm{C}_{60}$ materials, the cost of using power transformers may be further increased. Although $\mathrm{C}_{60}$ is not toxic to the human body, whether nano-sized $\mathrm{C}_{60}$ in insulating oil causes environmental damage must be clarified.

\section{Conclusions}

Based on the test and analysis results, the following conclusions are reached:

The $\mathrm{C}_{60}$ nanoparticles are round, and their diameters are about $30 \mathrm{~nm}$. The average particle size of the newly prepared CMIO is $305.7 \mathrm{~nm}$, and the average particle size of the CMIO kept for 12 months is $320.1 \mathrm{~nm}$. Without the use of any surface modifiers, the particle size of CMIO kept for 12 months did not change significantly. Meanwhile, the average zeta potential ( $\mathrm{pH}=7,100 \mathrm{mg} / \mathrm{L}$ ) of $\mathrm{CMIO}$ is $-41.3 \mathrm{mV}$. Therefore, the dispersion stability of CMIO is good. CMIO has better stability compared with traditional nano-modified insulating oil, especially without the use of surface modifiers for nanoparticles.

The positive lightning impulse breakdown voltage of $\mathrm{CMIO}$ is not as high as that of some traditional nanoparticles (such as $\mathrm{Fe}_{3} \mathrm{O}_{4}$ and $\mathrm{TiO}_{2}$ ), but the negative lightning impulse breakdown voltage of $\mathrm{CMIO}$ is increased. This finding is good news for the engineering application of nano-modified insulating oil. According to our test results, the optimum concentration for improving the comprehensive breakdown performance of $\mathrm{CMIO}$ is $150 \mathrm{mg} / \mathrm{L}$.

The dielectric constant of CMIO is slightly higher than that of FO across the entire test frequency range. In the low frequency range (less than $1 \mathrm{~Hz}$ ), the dielectric loss factor of CMIO is slightly higher than that of FO. The dielectric loss factors of all the samples increase with decreasing frequency. According to the TSC measured curve, the peak separation, and fitting calculation results, the peak current of CMIO (4.84 pA) is 1.81 times that of FO $(2.68 \mathrm{pA})$, the trap level of CMIO $(0.718 \mathrm{eV})$ is 1.42 times that of $\mathrm{FO}(0.505 \mathrm{eV})$, and the trap charge of CMIO $(5.12 \mathrm{nC})$ is 1.41 times that of $\mathrm{FO}(3.63 \mathrm{nC})$ at peak I. We believe that a substantial number of electrons are trapped by the deep and dense traps in $\mathrm{CMIO}$, and thus the development of streamers is disrupted and breakdown voltage increases.

The breakdown performance of CMIO is higher than that of FO because of the changes in the trap parameters, the strong electron capture ability of $\mathrm{C}_{60}$, and its absorption capacity for photons. We believe that the inhibition of $\mathrm{C}_{60}$ nanoparticles on the photoionization process is the reason for the improvement in the negative impulse breakdown performance of CMIO.

Author Contributions: Conceptualization, J.C. and P.S.; Methodology, J.C. and P.S.; Investigation, J.C.; Writing-Original Draft Preparation, J.C.; Writing-Review and Editing, W.S. and P.S.; Visualization, J.C., P.S., Q.S. and L.Y.; Validation J.C. and C.L.

Funding: This research was supported by the National Key Basic Research Program of China (2017YFB0902702), the National Basic Research Program (973 Program) (2015CB251003), and the National Natural Science Foundation of China (51707023 and 51837002).

Conflicts of Interest: The authors declare no conflicts of interest. 


\section{References}

1. Choi, S.U.S.; Eastman, J. Enhancing thermal conductivity of fluids with nanoparticles. In Proceedings of the ASME International Mechanical Engineering Congress and Exposition, San Francisco, CA, USA, 12-17 November 1995; pp. 66-74.

2. Fedele, L.; Colla, L.; Bobbo, S.; Barison, S.; Agresti, F. Experimental stability analysis of different water-based nanofluids. Nanoscale. Res. Lett. 2011, 6, 300-308. [CrossRef]

3. Viali, W.R.; Alcantara, G.B.; Sartoratto, P.P.C.; Soler, M.A.G. Investigation of the molecular surface coating on the stability of Insulating magnetic oils. J. Phys. Chem. C 2010, 114, 179-188. [CrossRef]

4. Choi, C.; Yoo, H.S.; Oh, J.M. Preparation and heat transfer properties of nanoparticle-in-transformer oil dispersions as advanced energy-efficient coolants. Curr. Appl. Phys. 2008, 8, 710-712.

5. Segal, V.; Hjortsberg, A.; Rabinovich, A.; Nattrass, D.; Raj, K. AC (60 Hz) and impulse breakdown strength of a colloidal fluid based on transformer oil and magnetite nanoparticles. In Proceedings of the IEEE International Symposium on Electrical Insulation, Arlington, VA, USA, 7-10 June 1998; pp. 619-622.

6. Sima, W.; Cao, X.; Yang, Q. Preparation of three transformer oil-based nanofluids and comparison of their impulse breakdown characteristics. Nanosci. Nanotech. Let. 2014, 6, 250-256. [CrossRef]

7. Segal, V.; Nattrass, D.; Raj, K. Accelerated thermal aging of petroleum-based ferrofluids. J. Magn. Mate. 1999, 201, 70-72. [CrossRef]

8. Wang, Q.; Rafiq, M.; Lv, Y.; Li, C.; Yi, K.J. Preparation of three types of transformer oil-based nanofluids and comparative study on the effect of nanoparticle concentrations on insulating property of transformer oil. J. Nanotechnol. 2016, 2016, 1-6. [CrossRef]

9. Rafiq, M.; Li, C.; Khan, I.; Hu, Z.; Lv, Y.; Yi, K. Preparation and breakdown properties of mineral oil based alumina nanofluids. In Proceedings of the IEEE International Conference on Emerging Technologies, Peshawar, Pakistan, 19-20 December 2015; pp. 1-3.

10. Lv, Y.; Ge, Y.; Li, C. Effect of $\mathrm{TiO}_{2}$ nanoparticles on streamer propagation in transformer oil under lightning impulse voltage. IEEE Trans. Dielectr. Electr. Insul. 2016, 23, 2110-2115. [CrossRef]

11. Rafiq, M.; Li, C.; Lv, Y.; Yi, K.; Ikram, A. Breakdown characteristics of transformer oil based silica nanofluids. In Proceedings of the 19th International Multi-Topic Conference, Islamabad, Pakistan, 5-6 December 2016; pp. 302-305.

12. Liu, R.; Pettersson, L.A.A.; Auletta, T.; Hjortstam, O. Fundamental research on the application of nano dielectrics to transformers. In Proceedings of the Annual Report Conference on Electrical Insulation and Dielectric Phenomena, Cancun, Mexico, 16-19 October 2011; pp. 423-427.

13. Rakov, V.A. Lightning parameters for engineering applications (keynote speech). In Proceedings of the 2010 Asia-Pacific International Symposium on Electromagnetic Compatibility, Beijing, China, 12-16 April 2010; pp. 1120-1123.

14. Sun, P.; Sima, W.; Zhang, D.; Jiang, X.; Chen, Q.; Chen, J. Impact of wavefront time of microsecond impulse on the breakdown voltage of oil impregnated paper: Mechanism analysis. IEEE Trans. on Dielectr. Electr. Insul. 2018, 25, 1706-1715. [CrossRef]

15. Sartoratto, P.P.C.; Neto, A.V.S.; Lima, E.C.D. Preparation and electrical properties of oil-based magnetic fluids. J. Appl. Phys. 2005, 97, 10Q917. [CrossRef]

16. Mergos, J.; Athanassopoulou, M.; Argyropoulos, T. Dielectric properties of nanopowder dispersions in paraffin oil. IEEE Trans. Dielectr. Electr. Insul. 2012, 19, 1502-1507. [CrossRef]

17. Wang, X.; Woo, H.K.; Wang, L. Vibrational cooling in a cold ion trap: Vibrationally resolved photoelectron spectroscopy of cold $\mathrm{C}_{60}(-)$ anions. J. Chem. Phys. 2005, 123, 051106. [CrossRef]

18. Sun, P.; Sima, W.; Chen, J. An application area of $\mathrm{C}_{60}$ : Overall improvement of insulating oil's electrical performance. Appl. Phys. Lett. 2018, 112, 142902. [CrossRef]

19. Yanilkin, V.V.; Gubskaya, V.P.; Morozov, V.I. Electrochemistry of fullerenes and their derivatives. Russ. J. Electrochem. 2003, 39, 1147-1165. [CrossRef]

20. Rao, A.; Zhou, P.; Wang, K. Photoinduced polymerization of solid $C_{60}$ films. Science 1993, 259, $955-957$. [CrossRef]

21. Sivaraman, N.; Dhamodaran, R.; Kaliappan, I. Solubility of $C_{60}$ in organic solvents. J. Org. Chem. 1992, 57, 6077-6079. [CrossRef] 
22. Ruoff, R.S.; Tse, D.S.; Malhotra, R. Solubility of fullerene $\left(C_{60}\right)$ in a variety of solvents. J. Phys. Chem. 1993, 97, 3379-3383. [CrossRef]

23. ASTM. Standard Test Method for Dielectric Breakdown Voltage of Insulating Oils of Petroleum Origin under Impulse Conditions; ASTM D3487-2000(II); ASTM International: West Conshohocken, PA, USA, 2000.

24. Iio, Y.; Kurihara, K.; Matsuyama, F. Photopolymerization of $\mathrm{C}_{60}$ crystal synthesized from organic solution. J. Phys. 2009, 159, 012019.

25. Akhlaghi, S.; Pourrahimi, A.M. Effects of ageing conditions on degradation of acrylonitrile butadiene rubber filled with heat-treated $\mathrm{ZnO}$ star-shaped particles in rapeseed biodiesel. Polym. Degrad. Stabil. 2017, 138, 27-39. [CrossRef]

26. IEC. Insulating Liquids-Determination of the Breakdown Voltage at Power Frequency-Test Method; IEC 60156-1995; IEC: Geneva, Switzerland, 1995.

27. Liu, Q.; Wang, Z. Breakdown and withstand strengths of ester transformer liquids in a quasi-uniform field under impulse voltages. IEEE Trans. Dielectr. Electr. Insul. 2013, 20, 571-579. [CrossRef]

28. Chen, R. Analysis of Thermally Stimulated Processes; Pergamon: Oxford, NY, USA, 1981.

29. Zhong, Y.; Lv, Y.; Li, C. Insulating properties and charge characteristics of natural ester fluid modified by $\mathrm{TiO}_{2}$ semiconductive nanoparticles. IEEE Trans. Dielectr. Electr. Insul. 2013, 20, 135-140. [CrossRef]

30. Vandsburger, L. Synthesis and Covalent Surface Modification of Carbon Nanotubes for Preparation of Stabilized Nanofluid Suspensions. Ph.D. Thesis, McGill University, , Montreal, QC, Canada, 2009.

31. Ghadimi, A.; Saidur, R.; Metselaar, H.S.C. A review of nanofluid stability properties and characterization in stationary conditions. Int. J. Mass. Tran. 2011, 54, 4051-4068. [CrossRef]

32. Chen, K.L.; Elimelech, M. Relating Colloidal Stability of Fullerene $\left(\mathrm{C}_{60}\right)$ Nanoparticles to Nanoparticle Charge and Electrokinetic Properties. Environ. Sci. Technol. 2009, 43, 7270-7276. [CrossRef] [PubMed]

33. Pourrahimi, A.M.; Liu, D.; Pallon, L.K.H. Water-based synthesis and cleaning methods for high purity ZnO nanoparticles - comparing acetate, chloride, sulphate and nitrate zinc salt precursors. RSC. Adv. 2014, 4, 35568. [CrossRef]

34. Gallagher, S.H.; Armstrong, R.S.; Lay, P.A. Solvent Effects on the Electronic Spectrum of C60. J. Phys. Chem. 1995, 99, 5817-5825. [CrossRef]

35. Lee, J.H.; Hwang, K.S.; Jang, S.P. Effective viscosities and thermal conductivities of aqueous nanofluids containing low volume concentrations of Al2O3 nanoparticles. Int. J. Heat. Mass. Tran. 2008, 51, 2651-2656. [CrossRef]

36. Sima, W.; Sun, P.; Yang, Q. Study on the accumulative effect of repeated lightning impulses on insulation characteristics of transformer oil impregnated paper. IEEE Trans. Dielectr. Electr. Insul. 2014, 21, 1933-1941. [CrossRef]

37. Sami, S.; Haase, P.A.B.; Alessandri, R. Can the dielectric constant of fullerene derivatives be enhanced by side chain manipulation? a predictive first principles computational study. J. Phys. Chem. A. 2018, 122, 3919-3926. [CrossRef] [PubMed]

38. Singh, S.D.; Mazumdar, P.S.; Gartia, R.K. The determination of the trapping parameters of a thermoluminescence peak by using the Kirsh method. J. Phys. D: Appl. Phys. 1998, 31, 231-234. [CrossRef]

39. Hoogenboom, J.E.; Devries, W.; Dielhof, J.B.J. Computerized analysis of glow curves from thermally activated processes. Appl. Phys. 1988, 64, 3193-3200. [CrossRef]

40. Lei, Q.; Wang, X.; Fan, Y. A new method of auto-separating thermally stimulated current. J. App. Phys. 1992, 72, 4254-4257. [CrossRef]

41. Sun, P.; Sima, W.; Zhang, D.; Jiang, X.; Zhang, H.; Yin, Z. Failure characteristics and mechanism of nano-modified oil-Impregnated paper subjected to repeated impulse voltage. Nanomaterials 2018, 8, 504. [CrossRef]

42. Pourrahimi, A.M.; Olsson, R.T.; Hedenqvist, M.S. The Role of Interfaces in Polyethylene/Metal-Oxide Nanocomposites for Ultrahigh-Voltage Insulating. Materials. Advanced. Mate. 2018, 30, 1703624. [CrossRef]

43. Min, D.; Cho, M.G.; Khan, A.R. Charge transport properties of dielectrics revealed by isothermal surface potential decay. IEEE Trans. Dielectr. Electr. Insul. 2012, 19, 1465-1473. [CrossRef]

44. Sessler, G.M.; Figueiredo, M.T.; Ferreira, G.F.L. Models of charge transport in electron-beam irradiated insulators. IEEE Trans. Dielectr. Electr. Insul. 2004, 11, 192-202. [CrossRef]

45. Kao, K.C. Dielectric Phenomena in Solids; Elsevier Academic: San Diego, CA, USA, 2004; pp. 381-509. 
46. Min, D.; Li, S. IEEE Trans. Simulation on the influence of bipolar charge injection and trapping on surface potential decay of polyethylene. Dielectr. Electr. Insul. 2014, 21, 1627-1636. [CrossRef]

47. Nelson, J.K. Dielectric Polymer Nanocomposites; Springer: New York, NY, USA, 2010.

48. Stauffer, D.; Aharony, A. Introduction to Percolation Theory; Taylor: London, UK, 1992.

49. Balberg, I.; Azulay, D.; Toker, D. Percolation and tunneling in composite materials. Int. J. Mod. Phys. B 2012, 18, 2091-2121. [CrossRef]

50. Hoang, A.T.; Pallon, L.; Liu, D.; Serdyuk, Y.V.; Gubanski, S.M.; Gedde, U.W. Charge Transport in LDPE Nanocomposites Part I-Experimental Approach. Polymers 2016, 8, 87. [CrossRef]

51. Hong, J.I.; Schadler, L.S.; Siegel, R.W. Rescaled electrical properties of ZnO/low density polyethylene nanocomposites. Appl. Phys. Lett. 2003, 82, 1956. [CrossRef]

52. Peimo, H.; Yabo, X.; Xuejia, Z. Electrical conductivity studies of a pure $\mathrm{C}_{60}$ single crystal. J. Phys. Condens. Mat. 1993, 5, 7013-7016. [CrossRef]

53. Hwang, J.G.; Zahn, M.; Sullivan, O.; Francis, M. Effects of nanoparticle charging on streamer development in transformer oil-based nanofluids. J. Appl. Phys. 2010, 107, 014310. [CrossRef]

54. Takada, T.; Hayase, Y.; Tanaka, Y. Space charge trapping in electrical potential well caused by permanent and induced dipoles for LDPE/MgO nanocomposite. IEEE Trans. Dielectr. Electr. Insul. 2008, 15, 152-160. [CrossRef]

(C) 2019 by the authors. Licensee MDPI, Basel, Switzerland. This article is an open access article distributed under the terms and conditions of the Creative Commons Attribution (CC BY) license (http://creativecommons.org/licenses/by/4.0/). 